Article

\title{
Evaluation of the Use of Sub-Pixel Offset Tracking Techniques to Monitor Landslides in Densely Vegetated Steeply Sloped Areas
}

\author{
Luyi Sun * and Jan-Peter Muller \\ University College London, Mullard Space Science Laboratory, Holmbury St. Mary, Surrey RH5 6NT, UK; \\ muller@ucl.ac.uk \\ * Correspondence: luyi.sun.12@ucl.ac.uk; Tel.: +44-1483-204-167; Fax: +44-1483-278-312 \\ Academic Editors: Zhenhong Li, Roberto Tomas, Zhong Lu, Richard Gloaguen and Prasad S. Thenkabail \\ Received: 1 June 2016; Accepted: 10 August 2016; Published: 17 August 2016
}

\begin{abstract}
Sub-Pixel Offset Tracking (sPOT) is applied to derive high-resolution centimetre-level landslide rates in the Three Gorges Region of China using TerraSAR-X Hi-resolution Spotlight (TSX HS) space-borne SAR images. These results contrast sharply with previous use of conventional differential Interferometric Synthetic Aperture Radar (DInSAR) techniques in areas with steep slopes, dense vegetation and large variability in water vapour which indicated around $12 \%$ phase coherent coverage. By contrast, sPOT is capable of measuring two dimensional deformation of large gradient over steeply sloped areas covered in dense vegetation. Previous applications of sPOT in this region relies on corner reflectors (CRs), (high coherence features) to obtain reliable measurements. However, CRs are expensive and difficult to install, especially in remote areas; and other potential high coherence features comparable with CRs are very few and outside the landslide boundary. The resultant sub-pixel level deformation field can be statistically analysed to yield multi-modal maps of deformation regions. This approach is shown to have a significant impact when compared with previous offset tracking measurements of landslide deformation, as it is demonstrated that SPOT can be applied even in densely vegetated terrain without relying on high-contrast surface features or requiring any de-noising process.
\end{abstract}

Keywords: landslide monitoring; sub-Pixel Offset Tracking (sPOT); TerraSAR-X High-resolution Spotlight data; Corner Reflectors vs. natural scatterers; densely vegetated terrain

\section{Introduction}

Remote sensing, especially in the microwave region, has become the most convenient and feasible tool widely applied in deformation mapping. In the Three Gorges Region (TGR), due to the often limited access to Global Positioning System (GPS) measurements, the high costs of skilled labour and instrumentation required, it is difficult to obtain sufficient local geodetic measurements [1]. The usage of satellite remote sensing data for landslide studies in the TGR can be traced back to the 1980s [2]. Due to the high humidity caused by the monsoon climate of this region, optical sensors are often limited in obtaining an effective time series of measurements. A Synthetic Aperture Radar (SAR), which is able to work both day and night during all weather conditions and which repeatedly acquires time series of high-resolution images covering large areas, has been recognized as an effective and powerful sensor for landslide monitoring $[1,3]$.

The differential Interferometric SAR (DInSAR), which is capable of detecting surface deformation over a large area in the direction of the satellite Line of Sight (LOS) with a centimetre-to-millimetre precision, has been extensively applied to monitor volcanic activities, earthquakes, mining deformations, glacier movement, subsidence and landslides [4-13]. Time series algorithms have 
been developed to extend the use of DInSAR for temporal evolution of ground deformation, which can be essentially divided into two broad categories: the Persistent Scatterer (PS) InSAR [14-16] and Small Baseline Subset (SBAS) $[17,18]$.

However, the applications of DInSAR/time series DInSAR in the Three Gorges Region are limited by the difficulties arising from steep slopes, dense vegetation cover and high humidity. The experiment using PS-InSAR with ENVISAT data to measure deformation in the TGR area did not find sufficient PS points [19], which lead to the failure of phase unwrapping [3]. The attempt of using PS-InSAR with ASAR images to monitor the Shuping landslide failed for the same reason [1]. Experiments applying the SBAS method on TerraSAR-X (TSX) data in the Three Gorge Region did not find significant dependence upon the perpendicular baseline or dramatic increase of reliable scatterers over time, suggesting the use of SBAS method has limited benefit in this case [20].

In addition, DInSAR measurements on the Shuping landslide yielded varied results in previous studies. Fu et al. obtained DInSAR measurements on 12 corner reflectors (CRs) $(-1-11 \mathrm{~cm}$ in 140 days) of the Shuping landslide using five ENVISAT ASAR images spanning from September 2005 to March 2006. The investigated period missed the most active period of the Shuping landslide [21]. Xia et al. used the same 12 CRs to derive linear displacement rates of 1-11 cm/year from September 2005 to June 2007 [22], in contradiction with the results of [21] with a different deformation rate but an overlapping observation period between September 2005 and March 2006. For the period between September 2005 and June 2007, extensometer measurements show $50-70 \mathrm{~cm} /$ year displacement with a dramatic increase from May to August 2007 [23], which is different from the linear trend monitored by PS-InSAR.

It should be noted there is a limitation of DInSAR with regard to the maximum detectable displacement. If no prior knowledge of the deformation is provided, which is usually the case, the implementation of phase unwrapping relies on an assumption that the phase difference between any two neighbouring pixels does not exceed $\pm \pi$. This implies the maximum detectable deformation per pixel is half wavelength. In addition, phase gradients larger than 0.5 fringes may cause large-scale unwrapping errors, which means the displacement gradient between two neighbouring pixels is limited to $1 / 4$ wavelength [24]. Thus, the maximum detectable displacement gradient (DDG) of InSAR measurements is

$$
D=\lambda / 4 \mu
$$

where $D$ denotes the maximum DDG, $\lambda$ is the wavelength of the SAR sensor and $\mu$ is the pixel size of the SAR images for classical interferometry, or distance between persistent scatterers for PS techniques. The value of $D$ depends on the satellite. For example, in the case of TerraSAR-X Hi-resolution Spotlight (with wavelength $0.031 \mathrm{~m}$, pixel size $0.456 \mathrm{~m}$ ) data, the maximum DDG is 0.0059 using a small multi-looking factor of 2. This means that over a ground distance of $1 \mathrm{~m}$ (about 1 pixel in the case of TSX Hi Res data), a displacement of $0.59 \mathrm{~cm}$ in one revisit cycle (11 days) will be underestimated even when given very high phase coherence. In a real scenario, the coherence is usually lower, especially in densely vegetated areas. The theoretical limit will drop with the coherence leading to further underestimation, which is the case in our study. Many slow-moving landslides ( 1.6 m/year as defined in $[25,26]$ and cases reported in $[27,28])$ can exceed this threshold of displacement gradient, especially near the landslide boundary.

The sub-pixel Offset Tracking (sPOT) technique (sometimes referred to as Pixel Offset Mapping) has previously been applied to monitor glacier movements, volcanic activities and co-seismic tears in the solid earth resulting from severe earthquakes to address the technical defects and limitations of conventional DInSAR techniques, particularly their sparse coverage and the impact of dense vegetative cover [29]. In the past, studies on offset tracking techniques to measure slope movements are dominated by using optically sensed imagery from spaceborne or airborne platforms [30-35].

For SAR sensors, initially medium resolution SAR imagery were employed in offset tracking for measurements of very large deformation (metres to tens of metres) [36-38]. Intensity Tracking 
(based on Normalized Cross Correlation) was proposed and implemented on a set of ERS-1/2 SAR data acquired from March 1992 to February 1996 in order to estimate the motion of Monacobreen in Northern Svalbard [36]. It indicated that in the case of various SAR missions (RADARSAT, ERS-2, ENVISAT, ALOS) with a more than 24 day revisit interval, intensity based tracking is the only technique able to correctly measure glacier movement. The work by [37] proposed a PO-SBAS approach using ENVISAT data to measure large displacements (several metres) occurring in the inner part of the Sierra Negra caldera due to the October 2005 eruption. This PO-SBAS approach attempted to minimize the perpendicular baseline via small baseline combinations of offset pairs. However, the TSX data employed in our study consistently has short baselines ranging from $12 \mathrm{~m}$ to $220 \mathrm{~m}$, so the benefit of creating a SBAS network is limited. With the availability of higher resolution SAR data, Manconi et al. obtained post-event deformation maps for emergency evaluation of a large, rapidly-moving (10-20 m) landslide [39-41]. The same PO-SBAS approach was applied to ascending and descending pairs of COSMO-SkyMed images to retrieve 3D deformation of the Montescaglioso landslide (Italy) of which the main movement occurred over 15-20 min with an average velocity of about $0.5-1 \mathrm{~m}$ per minute.

Sub-Pixel Offset Tracking has recently been employed to derive centimetre-level landslide rates in the Three Gorges Region using 1-3 m resolution space-borne SAR images. Li et al. [42] used four pairs of TSX HS images to derive 2D (azimuth and slant range) landslide displacement in the Three Gorges Region. The results indicate May-August 2009 was the most active period of the Shuping landslide. However, due to the impact of dense seasonal vegetation cover, some results still show false deformation features in the slant range direction. Singleton et al. [20] conducted further analysis focusing on the $540,000 \mathrm{~m}^{2}$ area centred on the landslide blocks. This work focused on the use of previously installed Corner Reflectors (CRs) with offset tracking, to derive a deformation magnitude for each CR in order to plot time series deformation curves, confirming a dramatic increase in landslide rates from May to August in 2009. However, it was pointed out that the errors associated with the corner reflector measurements are an order of magnitude lower than those calculated from densely vegetated terrain. Also, it was pointed out in [43] using ground-based SAR (GB-SAR) data to measure the displacement from artificial CRss, the main constraint of the offset tracking technique is the need of CRs. This raises a large question for the vast majority of regions where no CRs are available especially in densely vegetated terrain. The question arises: are sPOT techniques able to correctly measure landslide rates? This is the starting point of this study.

As the main objective of this study, the potential of using natural scatterers is assessed on deformation measurements using an offset tracking approach by combining sub-pixel cross-correlation with a time series statistical analysis, which makes a significant difference in that it does not rely on high contrast surface features (e.g., Corner Reflectors). Unlike the scenario of a very large deformation [36-38,44], this study aims to exploit the use of offset tracking with time series high-resolution SAR data covering two years, to derive the temporal evolution and spatial distribution of a slow-moving landslide with an active period of months and accumulative displacement of up to $1 \mathrm{~m}$ per year. The study area is characterized by dense vegetation cover on steep slopes, which causes rapid decrease of temporal correlation/low coherence of DInSAR on natural scatterers. Given the deformation velocity, the offsets caused by seasonal changes of vegetation cannot be ignored, which increases the challenge of the use of natural scatterers.

In this paper, sub-Pixel Offset Tracking is applied in monitoring ground deformation in densely vegetated terrain and concentrating on the evaluation of its general application in the vast majority of regions where CRs are not available. Firstly, the landslide displacement rates in the field site, Shuping landslide area, were measured from artificial CRs using the fully available 2 year time series TerraSAR-X (TSX) Hi-resolution Spotlight data acquired from February 2009-April 2010 and January 2012-February 2013. Secondly, the correlation between the landslide displacements and water level variations of the Three Gorges Reservoir were then analysed to infer a possible failure mechanism for the Shuping landslide. Finally, as a key part of this study, the capability of sPOT techniques for measuring ground displacements in densely vegetated areas was assessed by a statistical analysis 
of deformation magnitudes derived from natural scatterers on the whole landslide body. Based on the above analysis, an approach is proposed to extend the applications of sPOT to densely vegetated terrain without requiring artificial CRs.

\section{Study Site}

The Three Gorges Region (TGR) of China, which is located between latitude $28^{\circ} 32^{\prime} \mathrm{N}-31^{\circ} 44^{\prime} \mathrm{N}$ and longitude $105^{\circ} 44^{\prime} \mathrm{E}-111^{\circ} 39^{\prime} \mathrm{E}$, is the region directly or indirectly involved in the submersion of the water storage of the Three Gorges Project (TGP). It stretches along the Yangtze River including 16 county-level divisions of the Chongqing municipality and 4 divisions of the Hubei province. The Three Gorges Dam (TGD), located at Sandouping Town to the west of the city of Yichang, China, is one of the world's largest civil engineering structures, which blocks water to form a $660 \mathrm{~km}$ long and $\approx 1.1 \mathrm{~km}$ wide reservoir. The water level of the Yangtze River in the TGD rose from $66 \mathrm{~m}$ to $135 \mathrm{~m}, 156 \mathrm{~m}$ and eventually $175 \mathrm{~m}$ above sea level during the three impoundments in 2003, 2006 and 2009. The Three Gorges Project (TGP) does a remarkable job of generating a huge amount of electric power as well as controlling floods and improving the shipping capacity of the Yangtze River. However, the construction and operation of Three Gorges Dam resulted in a significant land use change, which altered energy and water budgets, affected the regional weather and climate patterns, and is linked to the dramatically increased geological hazards dominated by landslide activities in the Three Gorges Region [45-47]. Numerous landslide activities have occurred in residential areas with high population density, causing a lot of wasted resources and loss of property.

As the construction and operation of the Three Gorges Dam raised major concerns about its environmental impacts, a number of studies have been carried out on several topics, including terrestrial ecosystems, sedimentation, pollution, river discharges, regional climate and induced geological hazards dominated by landslides [48-53].

Most of the landslides which occurred in the Three Gorges Region are identified as being triggered by water, with the variations of reservoir water level and seasonal heavy rainfall being the two main factors [23,54].

The field site, Shuping landslide area, is located on the south bank of the Yangtze River near Shazhenxi Town, Zigui County with centre coordinates of $30.996^{\circ} \mathrm{N}, 110.609^{\circ} \mathrm{E}$ as indicated in Figure 1a. The Shuping landslide was identified as an ancient landslide during the field investigations before the construction of Three Gorges Dam [55]. This area is underlaid by muddy sandstone and sandy mudstone of the Triassic Badong formation. The landslide is composed of two blocks as marked in Figure $1 \mathrm{~b}$ facing the North, with a width of about $650 \mathrm{~m}$, elevation ranging from 65 to $400 \mathrm{~m}$, thickness of $40-70 \mathrm{~m}$, volume of about 20 million $\mathrm{m}^{3}$ and average slope varying from $22^{\circ}$ on the upper part to $35^{\circ}$ on the lower part [54]. The landslide area is characterised by terraced slopes densely covered with orange trees. The landscape photos of the Shuping landslide area in Figure 2 show cracks on the local infrastructure and one photo of one of the CRs is shown.

The Shuping landslide is a typical slope accumulation landslide where deformation has increased since the water impoundment of the Three Gorges Reservoir in 2003. In June 2003, significant deformation appeared on the slope and it acute from 8 February 2004 on. This serious deformation posed a significant danger to 580 inhabitants and 163 houses directly in its path and most of the inhabitants had moved of the landslide area by May 2004. According to GPS measurements, from January 2004-October 2006, when the reservoir water level varied between 135 and $145 \mathrm{~m}$, the ground deformation of Shuping landslide area was predominantly a combination of squirm and uniform deformation. The accumulative displacement reached $300 \mathrm{~mm}$ from August 2004 to August 2006, 250 mm from August 2006 to July 2007, 500 mm from August 2007 to February 2009, and 700 mm from February 2009 to February 2010 according to extensometer measurements along the centre line of eastern block $[23,54]$. Following this for every single year, the deformation magnitude periodically fluctuates with variations in the reservoir water level which also coincides with rainfall periodicity [56]. 


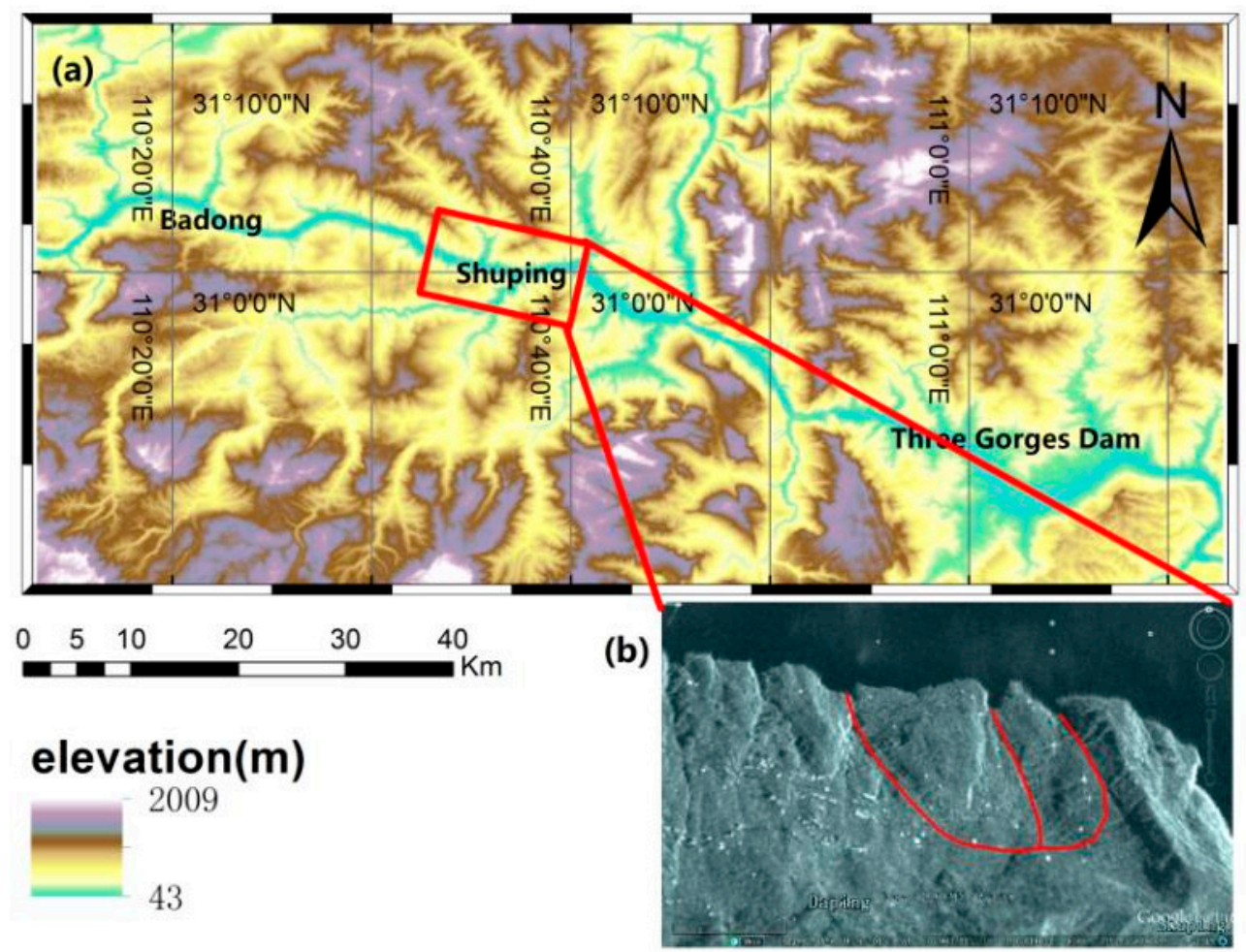

Figure 1. (a) Location of the Shuping landslide area; (b) Perspective view of landslide body shown in TerraSAR-X Hi-resolution Spotlight amplitude image superimposed in Google Earth with landslide blocks marked in red. Data source: TerraSAR-X @ DLR $<2009>$.

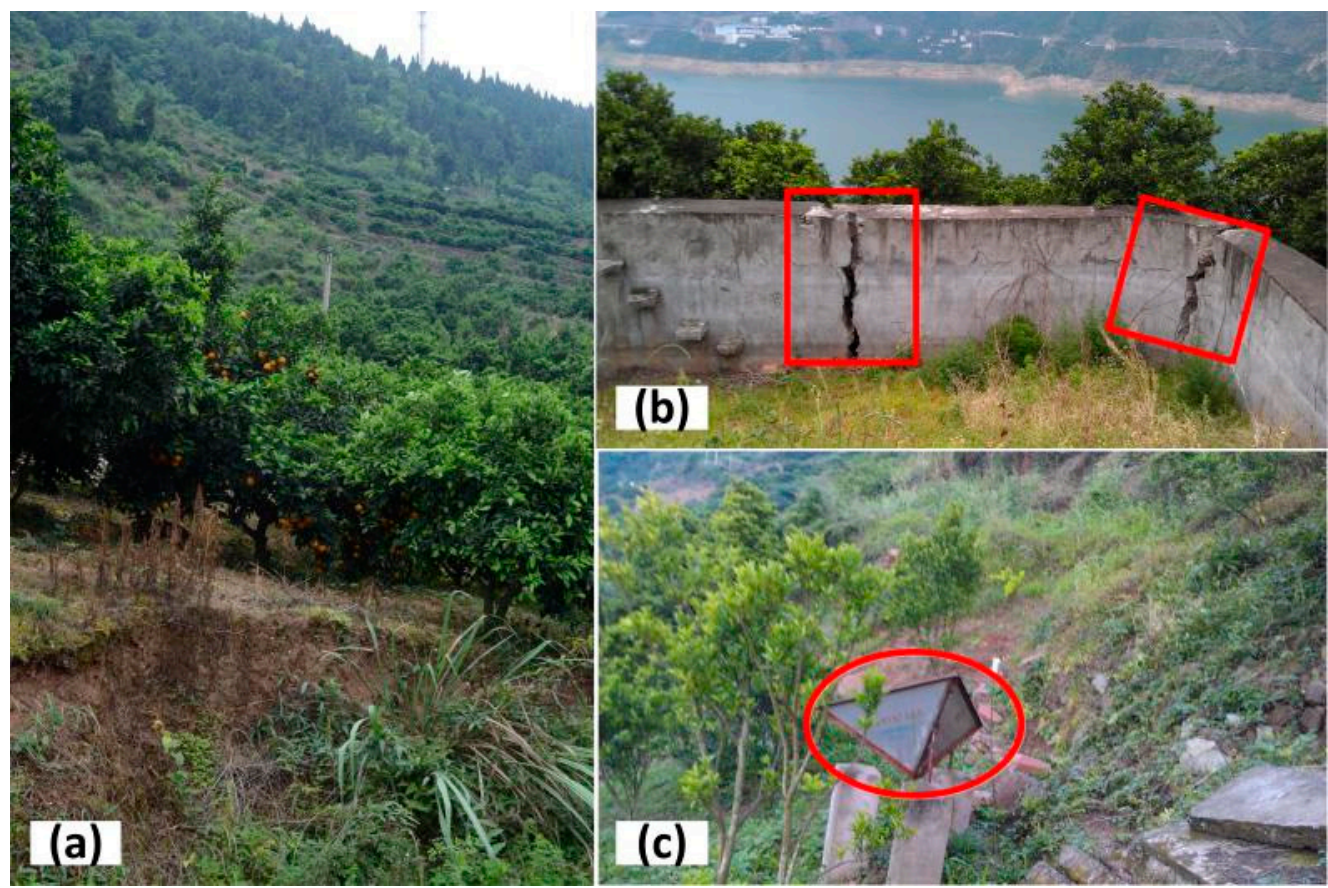

Figure 2. (a) Landscape of the landslide area; (b) Cracks on local infrastructure caused by the landslide; (c) one of the Corner Reflectors installed in the landslide area. Photos were taken during a field campaign in May 2014. 


\section{Data and Methods}

\subsection{Data}

The data employed in this research uses the TerraSAR-X Hi-resolution Spotlight (TSX HS) data. Fifty-seven archived TSX High-resolution Spotlight (HS) images were acquired from 21 February 2009-15 April 2009 and 2 January 2012-23 February 2013 over the Shuping landslide area in the Three Gorges Region. The extent of Spotlight data coverage is shown by the rectangle frame in Figure 1a. The metadata of the two annual time series of TSX HS data is listed in Table 1.

Table 1. Metadata of the two stacks of SAR data using the parameters from the first image of each stack, as the values remain very close for all subsequent acquisitions.

\begin{tabular}{ccc}
\hline & TerraSAR-X High-Resolution Spotlight Data \\
\hline Annual time series & 2009-2010 & 2012-2013 \\
\hline First acquisition & 21 February 2009 & 2 January 2012 \\
Last acquisition & 15 April 2010 & 23 February 2013 \\
Satellite orbit heading $\left(^{\circ}\right)$ & 190.552 & 189.617 \\
Wavelength $(\mathrm{m})$ & 0.031 & 0.031 \\
Incidence angle $\left(^{\circ}\right)$ & 43.690 & 43.602 \\
Range pixel spacing $(\mathrm{m})$ & 0.456 & 0.455 \\
Azimuth pixel spacing $(\mathrm{m})$ & 0.862 & 0.873 \\
Range resolution $(\mathrm{m})$ & 0.851 & 0.852 \\
\hline Azimuth resolution $(\mathrm{m})$ & 1.100 & 1.100 \\
\hline
\end{tabular}

\subsection{Methods: Sub-Pixel Offset Tracking (sPOT) Techniques}

An alternative to the use of SAR interferometry is to measure sub-pixel offsets between the SAR images. This can be achieved by FFT-based correlation (sometimes referred to as phase correlation) or Normalized Cross Correlation [57]. Due to the high noise level of SAR images, cross-correlation is more robust (found out in experiments) and therefore chosen for this study. One of the first offset tracking applications to the Three Gorges Area is shown by Li et al. [58] and more recently in [20]. We refer to these as sub-Pixel offset tracking (sPOT) techniques.

The Normalized Cross Correlation (NCC) derives a set of 2-dimensional (2D) offsets between pre-event and post-event images. NCC is a traditional method for image registration. It is applied to the intensity bands of cross event images to detect ground deformation through a measure of similarity between window pairs extracted from pre-event and post-event images. The similarity, which is defined as the correlation coefficient, is computed as follows:

$$
N C C=\frac{\sum_{m=1}^{N_{x}} \sum_{n=1}^{N_{y}}\left[\left(i_{1}(m, n)-\overline{i_{1}}\right) \cdot\left(i_{2}(m, n)-\overline{i_{2}}\right)\right]}{\sqrt{\sum_{m=1}^{N_{x}} \sum_{n=1}^{N_{y}}\left(i_{1}(m, n)-\overline{i_{1}}\right)^{2}} \sqrt{\sum_{m=1}^{N_{x}} \sum_{n=1}^{N_{y}}\left(i_{2}(m, n)-\overline{i_{2}}\right)^{2}}}
$$

where $i_{1}$ and $i_{2}$ denote pre-event and post-event images with a two-dimensional offset $(a, b)$, which can be described as $i_{2}(x, y)=i_{1}(x-a, y-b) . N_{x} \times N_{y}$ is the correlation window size which can be modified by the application requirements. $\overline{i_{1}}$ and $\overline{i_{2}}$ are the mathematical expectation values of the cross-event image pair:

$$
\begin{aligned}
& \overline{i_{1}}=\frac{1}{N_{x} \times N_{y}} \sum_{m=1}^{N_{x}} \sum_{n=1}^{N y} i_{1}(m, n) \\
& \overline{i_{2}}=\frac{1}{N_{x} \times N_{y}} \sum_{m=1}^{N_{x}} \sum_{n=1}^{N y} i_{2}(m, n)
\end{aligned}
$$


The NCC method searches for maximum correlation (i.e., maximum similarity) between window pairs formed by the pre-event and post-event images. Those window pairs for which a maximum correlation detected, are considered as corresponding pairs. After locating the corresponding pixels in the master and slave images, the $2 \mathrm{D}$ offsets of the slave image w.r.t. the master image can be obtained. To achieve a sub-pixel accuracy of correlation, two categories of approaches are usually used: (1) image intensities are oversampled prior to cross-correlation; (2) Without oversampling of the intensity bands, cross-correlation is done in the original image resolution, correlation peaks are located by polynomial fitting.

In this paper, all data are processed using the following step-by-step approach:

- For each data stack (2009-2010 and 2012-2013), the first acquisition was used as the master image. All the slave images were co-registered with respect to the same master to sub-pixel accuracy. Topographic distortions were modeled using a reference DEM (SRTM 1 arc-second global DEM) and precise orbital data and subtracted before the cross-correlation.

- Images are cropped to the landslide sub-area as inputs to the cross-correlation included within COSI_Corr [59-61]. At this point, the azimuth and range deformation fields are derived.

- Time series histograms of the range/azimuth deformation fields are plotted for the measurements derived on the landslide blocks and the measurements on the stable ground respectively.

- To correct the centroid shifts (mainly caused by the impact of vegetation) on every histogram, the time series histograms of the measurements from stable ground were all fitted by Gaussian functions. The centroid location of every Gaussian peak was taken as a reference to correct the centroid offsets for the corresponding histograms of range/azimuth offsets of the landslide area.

- From the change in histograms, the temporal evolution of the landslide is shown and the active period of the landslide can be identified, as well as the deformation scale.

- Using a correlation coefficient of 0.25 as the threshold, all pixels with correlation above this value are plotted to show the spatial distribution of azimuth and slant range offsets occurred in February 2009-April 2010 and January 2012-February 2013. The two maps can be plotted for each salve acquisition date in the data stack.

\section{Results}

\subsection{Time Series Landslide Rates Derived from Corner Reflectors (CRs) Using Sub-Pixel Offset Tracking}

Subsets of landslide sub-areas were cropped from 35 pairs of TerraSAR-X Hi-resolution Spotlight (TSX HS) images acquired from 21 February 2009-15 April 2010 and 20 pairs from 2 January 2012-23 February 2013. The sPOT method was applied to every co-registered subset pair using 20090221 and 20120102 images, respectively, as the common master image for each annual time series (i.e., 2009-2010 and 2012-2013, respectively), to retrieve deformations along the range (satellite line-of-sight) and the azimuth (along-track) direction. The acquisition dates and estimated baselines of employed data (in brackets) are listed in Tables 2 and 3 with each image named after the acquisition date in the format "yyyymmdd". 
Table 2. TSX HS data employed in 2009-2010 time series analysis.

\begin{tabular}{llll}
\hline Common Master & \multicolumn{3}{c}{ Slave (Perpendicular Baseline) } \\
\hline $20090304(192 \mathrm{~m})$ & $20090315(125 \mathrm{~m})$ & $20090326(040 \mathrm{~m})$ \\
\hline $20090406(028 \mathrm{~m})$ & $20090417(080 \mathrm{~m})$ & $20090428(050 \mathrm{~m})$ \\
$20090509(040 \mathrm{~m})$ & $20090520(041 \mathrm{~m})$ & $20090531(051 \mathrm{~m})$ \\
\hline $20090611(052 \mathrm{~m})$ & $20090622(125 \mathrm{~m})$ & $20090703(074 \mathrm{~m})$ \\
$20090714(072 \mathrm{~m})$ & $20090725(137 \mathrm{~m})$ & $20090805(071 \mathrm{~m})$ \\
\hline $20090816(120 \mathrm{~m})$ & $20090827(074 \mathrm{~m})$ & $20090907(040 \mathrm{~m})$ \\
$20090918(156 \mathrm{~m})$ & $20090929(180 \mathrm{~m})$ & $20091010(046 \mathrm{~m})$ \\
\hline $20091112(085 \mathrm{~m})$ & $20091123(017 \mathrm{~m})$ & $20091204(089 \mathrm{~m})$ \\
\hline $20091215(043 \mathrm{~m})$ & $20091226(066 \mathrm{~m})$ & $20100106(105 \mathrm{~m})$ \\
\hline $20100117(145 \mathrm{~m})$ & $20100128(033 \mathrm{~m})$ & $20100219(150 \mathrm{~m})$ \\
\hline $20100304(097 \mathrm{~m})$ & $20100313(220 \mathrm{~m})$ & $20100324(102 \mathrm{~m})$ \\
\hline $20100404(111 \mathrm{~m})$ & $20100415(123 \mathrm{~m})$ & \\
\hline
\end{tabular}

Table 3. TSX HS data employed in 2012-2013 time series analysis.

\begin{tabular}{llll}
\hline Common Master & \multicolumn{3}{c}{ Slave (Perpendicular Baseline) } \\
\hline & $20120113(035 \mathrm{~m})$ & $20120124(012 \mathrm{~m})$ & $20120204(094 \mathrm{~m})$ \\
\hline $20120215(074 \mathrm{~m})$ & $20120226(055 \mathrm{~m})$ & $20120308(021 \mathrm{~m})$ \\
$20120319(081 \mathrm{~m})$ & $20120330(029 \mathrm{~m})$ & $20120421(058 \mathrm{~m})$ \\
\hline $20120524(064 \mathrm{~m})$ & $20120615(191 \mathrm{~m})$ & $20120820(183 \mathrm{~m})$ \\
$20120922(083 \mathrm{~m})$ & $20121025(002 \mathrm{~m})$ & $20121127(082 \mathrm{~m})$ \\
\hline $20130110(025 \mathrm{~m})$ & $20130121(040 \mathrm{~m})$ & $20130201(160 \mathrm{~m})$ \\
\hline
\end{tabular}

There have been artificial CRs installed in the Three Gorges Region since 2000 [62]. Seventeen CRs are identified in the Shuping landslide area from the TSX Hi-resolution Spotlight image as shown in Figure 3.

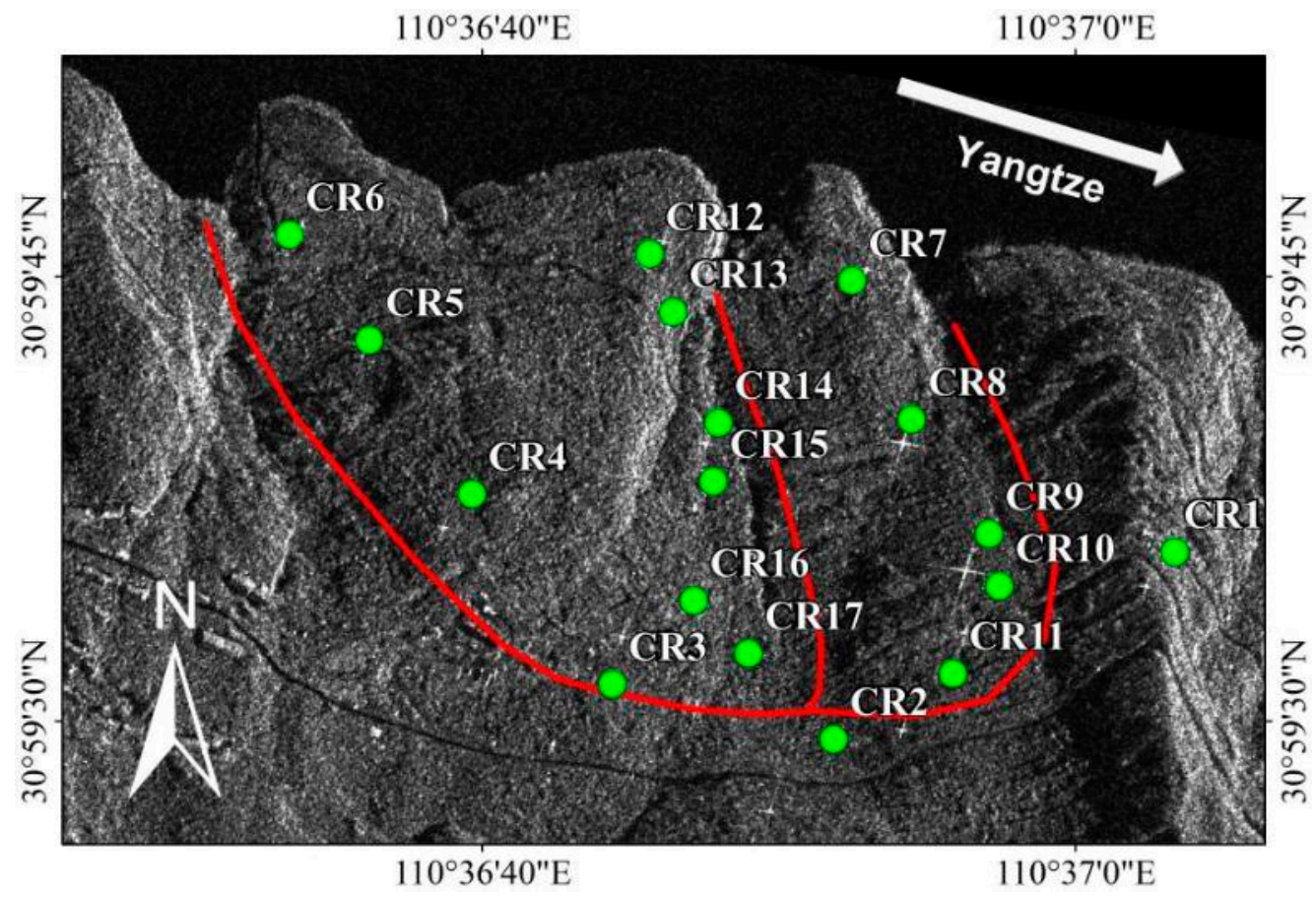

Figure 3. Location of Corner Reflectors in the Shuping landslide area, shown in TerraSAR-X amplitude, with landslide boundaries corresponding to the two landslide blocks. Data source: TerraSAR-X (C) DLR <2009>. 
The correlation coefficients of all CRs are examined prior to the time series analysis. As shown in Figure 4, the correlation coefficient of CR3 is very low (around 0.2) throughout the 2012-2013 stack, which will lead to inconclusive cross-correlation. CR5 shows inconsistencies in the correlation coefficient, because it is missing from the SAR amplitude images during 15 June 2012-10 January 2013 possibly due to reinstallation or orientation adjustment. Thus, CR3 and CR5 were both excluded from the analysis of the two annual time series.

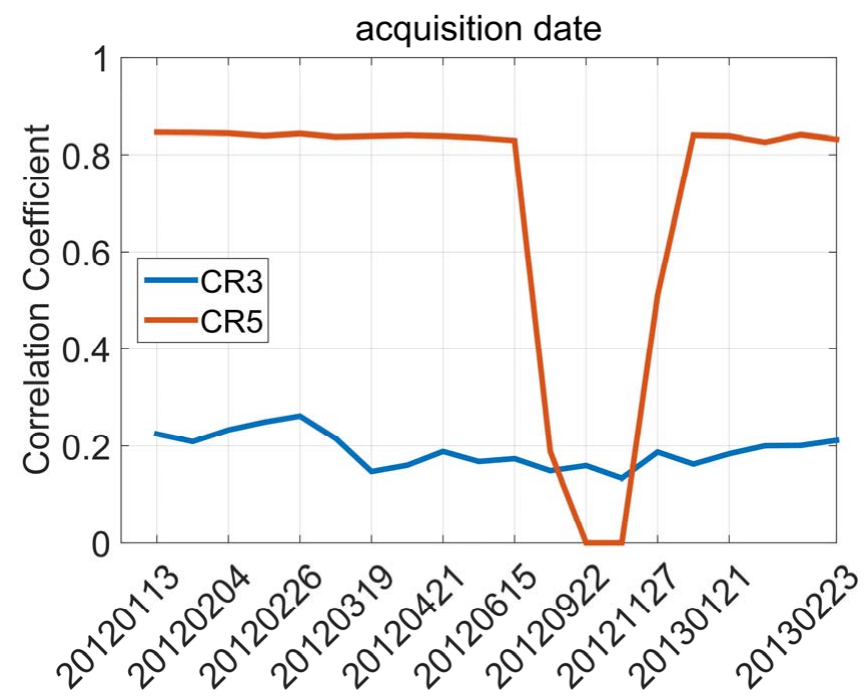

Figure 4. Correlation coefficients of CRs derived by sub-pixel offset tracking in the Shuping landslide area. Acquisition date is displayed in the format of 'yyyymmdd'.

The deformation magnitudes of the remaining 14 CRs (as shown in Figure 3) were extracted to plot time series landslide rates. No de-noising or filtering steps were applied. As all data was acquired with right looking SAR in the descending mode, the negative magnitude of the azimuth deformation corresponds to the reverse along-track direction (predominantly to the North) and the positive magnitude of range deformation represents the movement away from the sensor.

The topographic distortions of the range offsets were modeled by using a reference DEM and precise orbital data and subtracted before cross-correlation. To reduce the background noise, CR1 was taken as a reference point for all the other CRs as it is identified as located on the stable ground.

The two annual time series of landslide rates derived from CRs are shown in Figures 5 and 6.
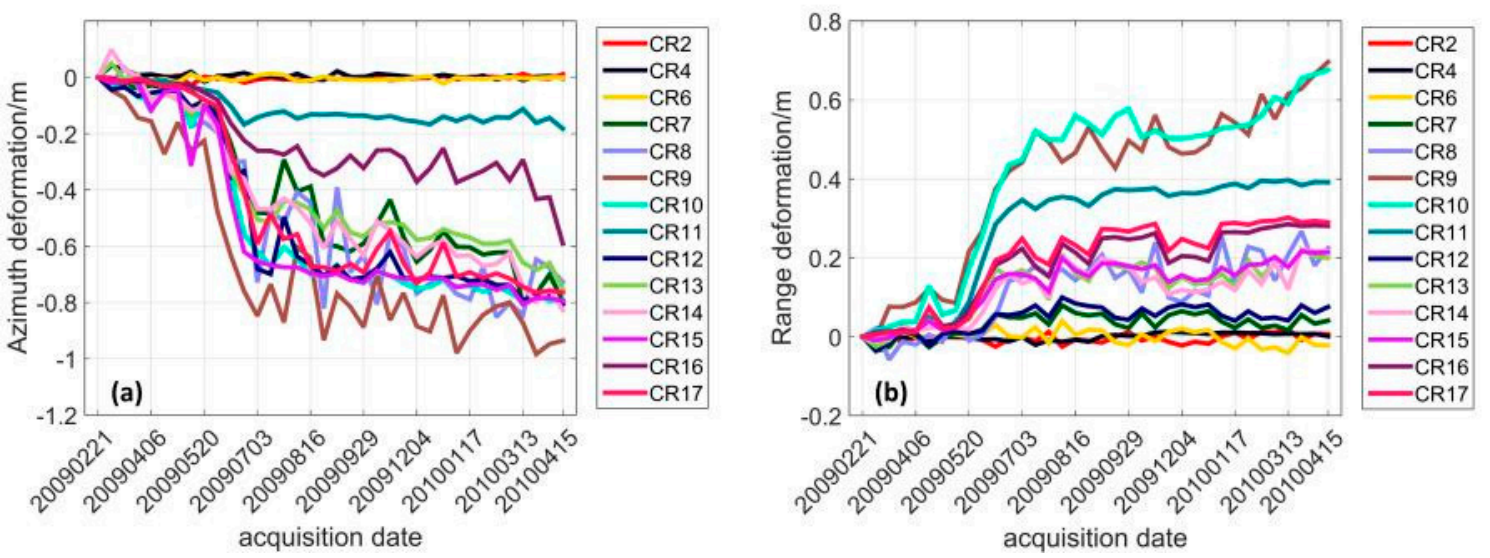

Figure 5. A 2009-2010 time series deformation measured from Corner Reflectors: (a) Azimuth deformation; (b) Slant range deformation. Acquisition date is displayed in the format of 'yyyymmdd'. 

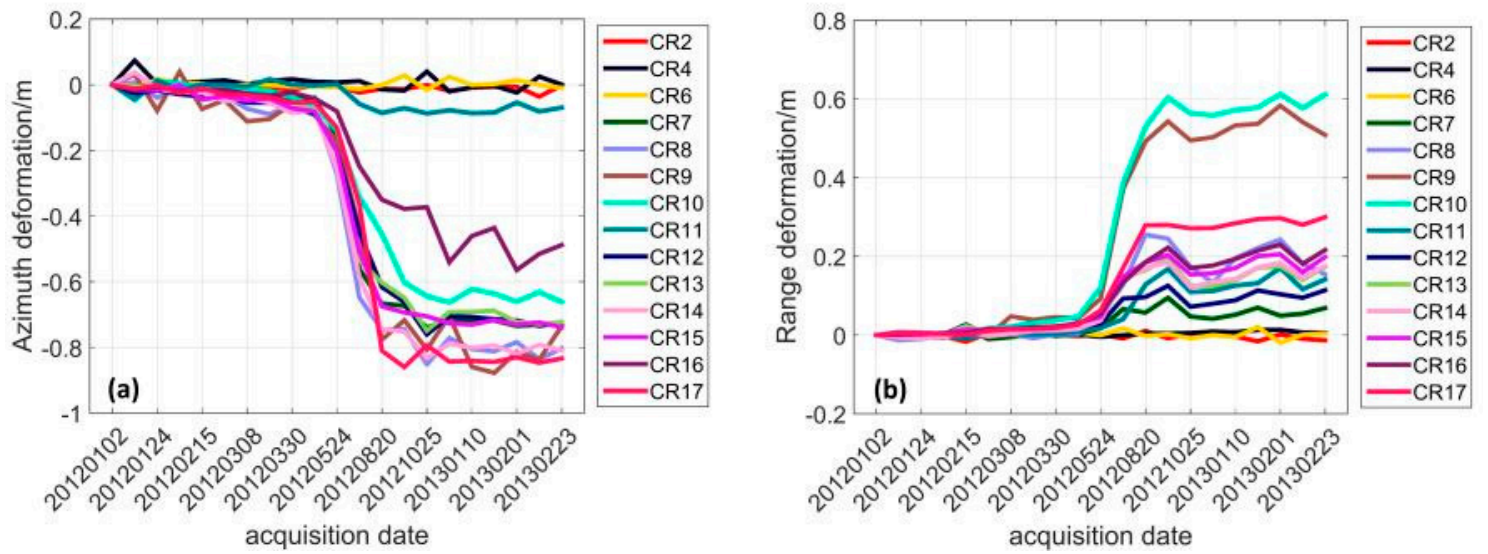

Figure 6. A 2012-2013 time series deformation measured from Corner Reflectors: (a) Azimuth deformation; (b) Slant range deformation. Acquisition date is displayed in the format of 'yyyymmdd'.

\subsection{The Correlation Between the Landslide Deformation and Water Level Variations}

To study the relationship between the landslide displacements and the operation of the Three Gorges Dam, the derived landslide rates of CR9 and CR15 (taken as examples due to the typical deformation patterns) were plotted against water level measurements of the Three Gorges Reservoir for the same time periods, from February 2009-April 2010 and January 2012-February 2013. The water level measurements can be accessed from the Three Gorges Corporation website: http://www.ctg.com.cn/inc/sqsk.php.

As shown in Figures 7 and 8, the water level measurements over the same time period show a consistent seasonal pattern with a lower level in the flood season and normal levels in other seasons. This is strongly correlated with the active period of the Shuping landslide. There is no correlation between the displacements and the big rise in water levels in September, this will be addressed in the Discussion Section 5.4.
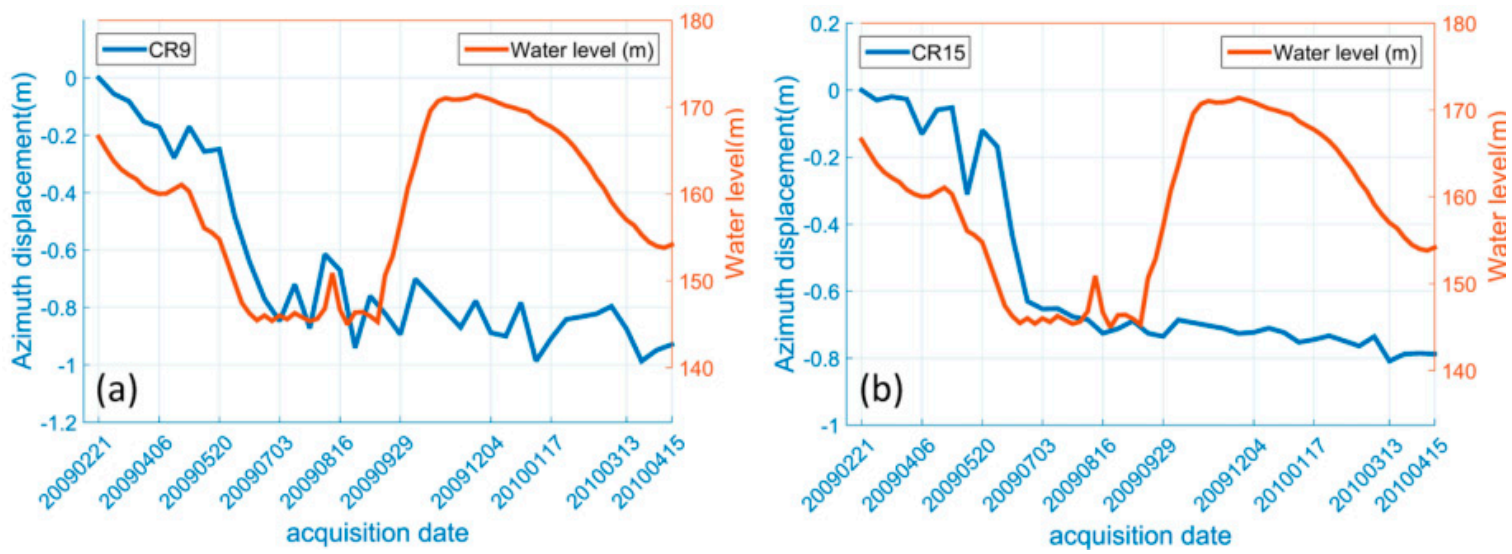

Figure 7. (a) Azimuth displacements of CR9 versus water level measurements of Three Gorges Reservoir from February 2009 to April 2010; (b) Azimuth displacements of CR15 versus water level measurements of Three Gorges Reservoir from February 2009 to April 2010. Acquisition date is displayed in the format of 'yyyymmdd'. 

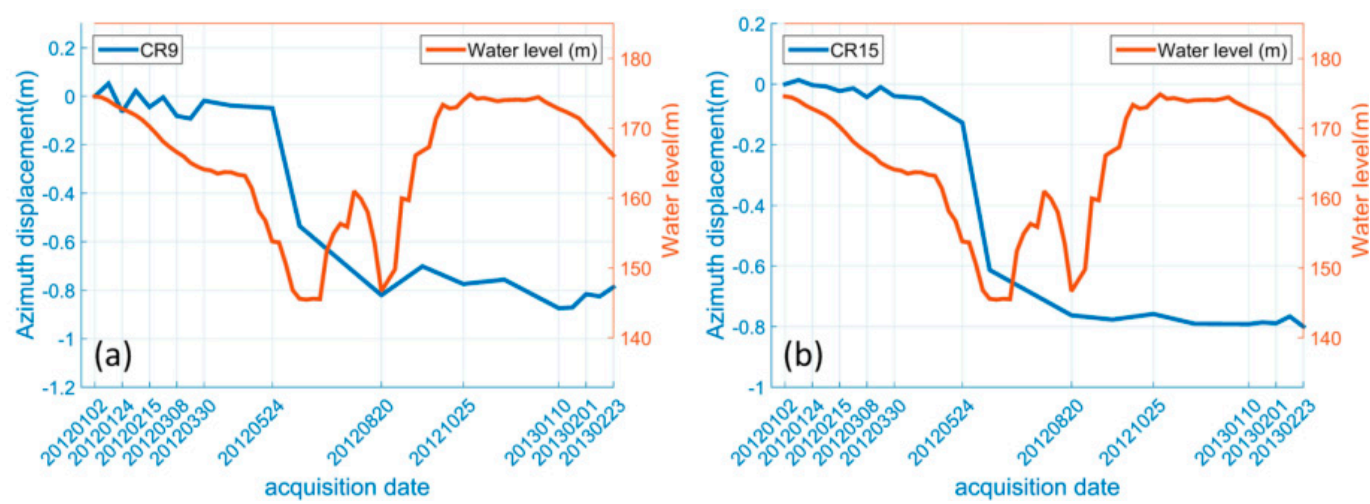

Figure 8. (a) Azimuth displacements of CR9 versus water level measurements of Three Gorges Reservoir from January 2012 to February 2013; (b) Azimuth displacements of CR15 versus water level measurements of Three Gorges Reservoir from January 2012 to February 2013. Acquisition date is displayed in the format of 'yyyymmdd'.

\subsection{Assessment of Using Natural Scatterers with sPOT Techniques to Monitor Landslide Movement in Densely Vegetated Terrain}

Artificial CRs are not widely available along the banks of Yangtze River due to the large number and scale of landslides in the Three Gorges Area and the high costs of the associated building works as well as the huge difficulties in physical access [63-65]. In order to assess the use of sPOT techniques in densely vegetated terrain without relying on CRs, statistics of deformation measurements derived from natural scatterers were compared to those derived from CRs. The analysis was conducted in the $540,000 \mathrm{~m}^{2}$ area covering the two landslide blocks. All contributions from CRs were masked out from the original azimuth/range deformation output. No de-noising or filtering steps were applied. Results are shown in Figure 9.
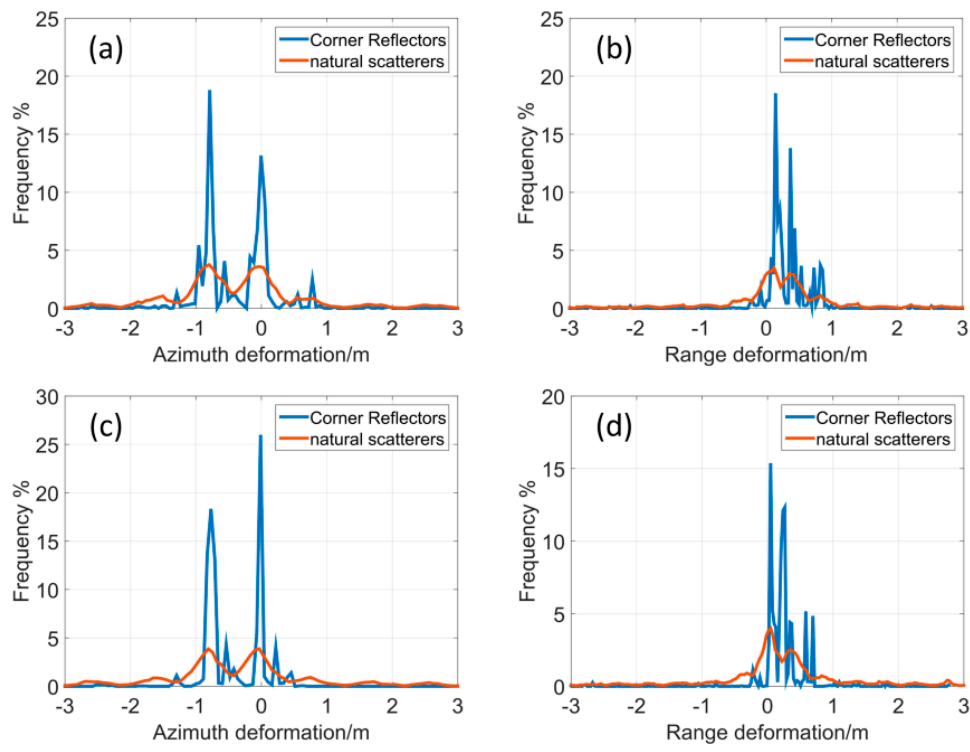

Figure 9. (a) Histograms of azimuth deformation derived from 21 February 2009-15 April 2010 image pair from natural scatterers vs. CRs inside the landslide boundary; (b) Histograms of range deformation derived from the 21 February 2009-15 April 2010 image pair from natural scatterers vs. CRs inside the landslide boundary; (c) Histograms of azimuth deformation derived from 2 January 2012-23 February 2013 image pair from natural scatterers vs. CRs inside the landslide boundary; (d) Histograms of range deformation derived from the 2 January 2012-23 February 2013 image pair from natural scatterers vs. CRs inside the landslide boundary. Modified from [66]. 
From the comparisons of displacement histograms shown in Figure 9, we can observe that measurements from natural scatterers show the same range of deformation magnitudes as those derived from CRs.

\subsection{Statistical Analysis Combined with sPOT for General Use in Landslide Monitoring in Densely Vegetated Areas}

The histograms of azimuth/range deformation measured from the natural scatterers of the landslide blocks and adjacent stable ground are compared in Figure 10.
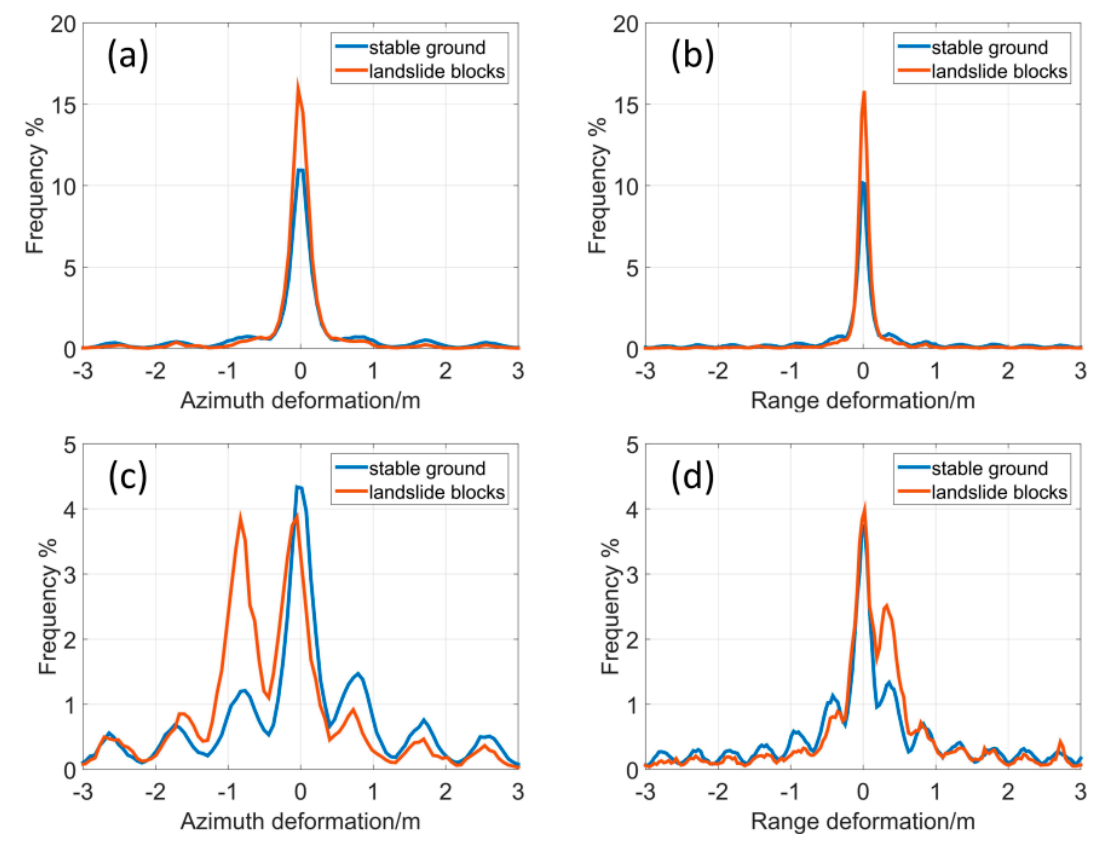

Figure 10. Comparison of azimuth/range deformation histograms of natural scatterers derived from stable ground and landslide blocks; (a) azimuth displacement derived from 2 January 2012-13 January 2012 image pair; (b) range displacement derived from 2 January 2012-13 January 2012 image pair; (c) azimuth displacement derived from 2 January 2012-23 February 2013 image pair; (d) range displacement derived from 2 January 2012-23 February 2013 image pair.

In Figure 10a,b, before the occurrence of the landslide the histograms of the 2D deformation measured from landslide blocks and stable ground have very similar distributions with only one main lobe centred on a zero offset. After the displacements as shown in Figure 10c, d the histogram of the stable ground still retains a single, main lobe centred on the zero offset with increased side lobes (probably due to the vegetation impacts during the over one year interval). The histogram of landslide blocks has a dramatic impact in changing the distribution, with a secondary lobe centred on positive value for range displacement and negative value for azimuth displacement, in addition to very similar side lobes found in the histogram of the stable ground.

Following on from the above analysis, a new approach combining sub-pixel cross-correlation and statistical processing is proposed to monitor landslides in such challenging areas for general use when high-contrast surface features are very few or not available.

The processing flow of the new sPOT approach is shown in Figure 11. Firstly, using the annual time series data acquired from 21 February 2009-15 April 2010 with the image of 21 February 2009 as the master image and all the others as slave images; and the other annual time series data acquired from 2 January 2012-23 February 2013 with the image of 2 January 2012 as the master image and all the others as slave images, co-registration was carefully applied to achieve $1 / 100-1 / 10$ pixel accuracy. Secondly, sub-pixel Cross Correlation was applied to the co-registered time series to derive range/azimuth deformation fields of the Shuping landslide. 


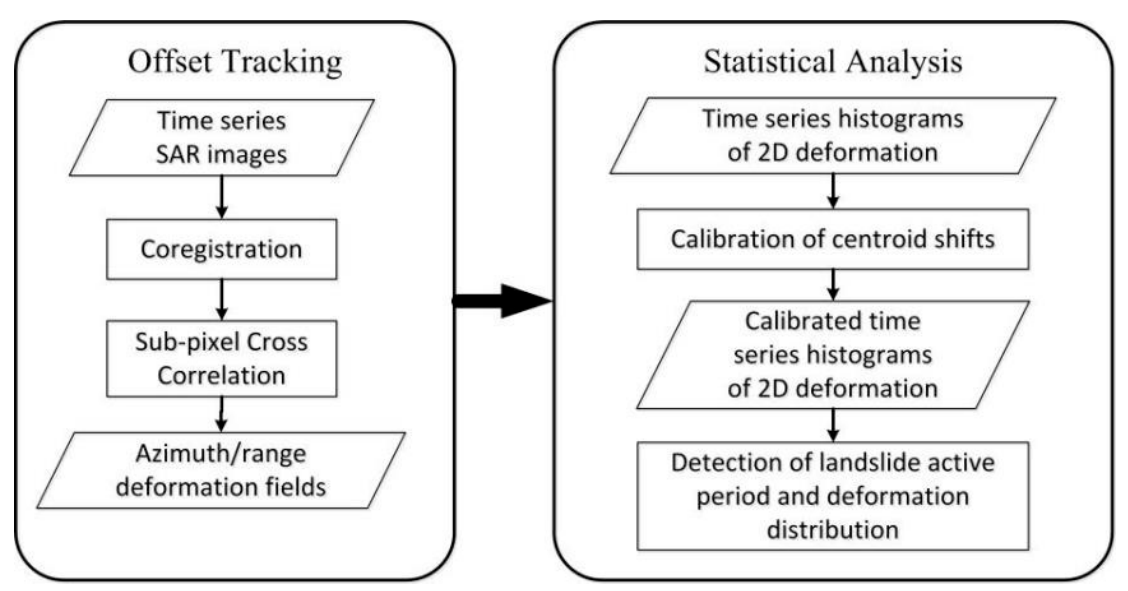

Figure 11. Workflow of the approach combining sPOT and statistical analysis.

To distinguish the measurements of CRs from natural scatterers and demonstrate the effectiveness of the proposed approach, all contributions from CRs in the range/azimuth deformation fields were masked out beforehand.

This approach applies statistical analysis to the derived deformation fields, by plotting histograms of range/azimuth time series offsets derived from landslide blocks. The constant offsets, showing as centroid shifts in the histograms of the stable area, were corrected by Gaussian fitting to the time series histograms of the range/azimuth offsets derived from the stable ground.

The Gaussian model to fit is given by

$$
\mathrm{y}=\sum_{i=1}^{n} a_{i} \exp \left[-\left(\frac{x-b_{i}}{c_{i}}\right)^{2}\right], \quad 1 \leq n \leq 8
$$

The number of Gaussian functions was increased one by one until the fit computation converged or reached the maximum number of fitting functions. Examples of the fitted Gaussian functions are plotted against the original histograms in Figure 12, showing the main lobes and secondary lobes are all fitted.
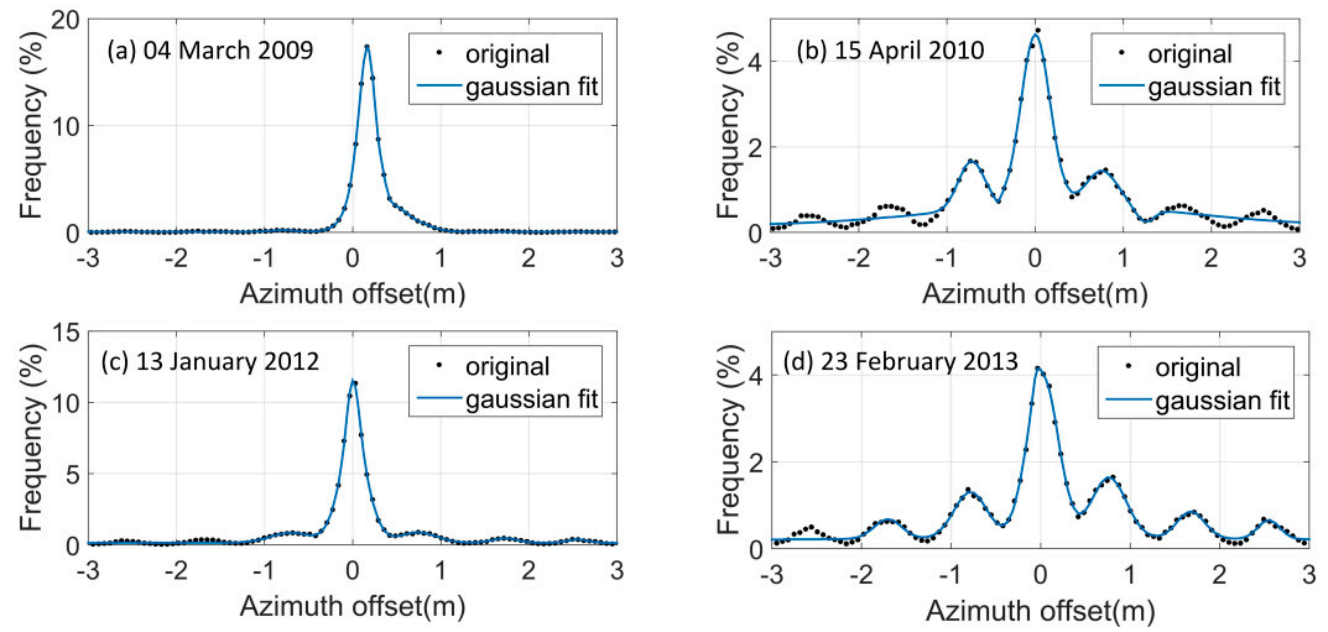

Figure 12. Gaussian fitted histogram vs. the original histogram of azimuth offsets derived from stable area (a) 4 March 2009; (b) 15 April 2010; (c) 13 January 2012; (d) 23 February 2013.

The centroid offsets of the Gaussian fitted deformation histograms derived from the 2009-2010 and 2012-2013 annual time series on the stable ground are shown in Figure 13. 

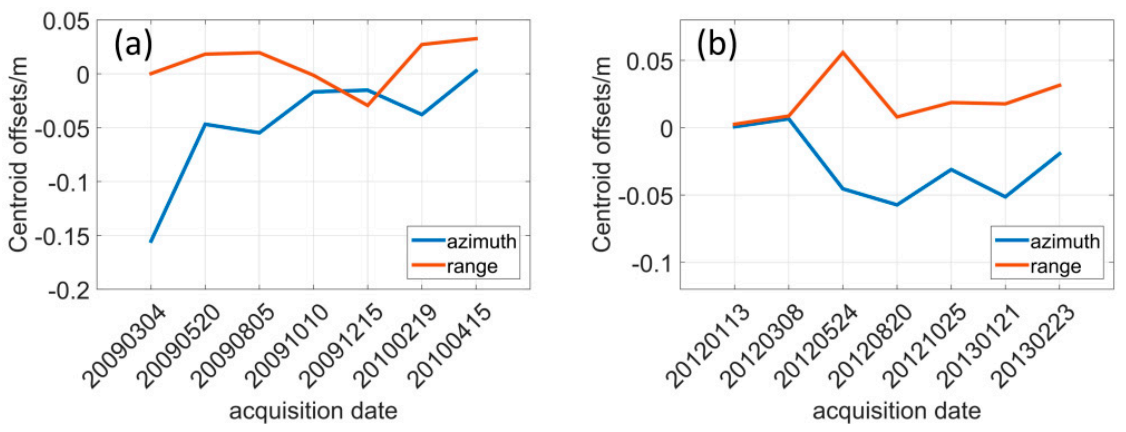

Figure 13. Centroid offsets of deformation histograms derived from natural scatterers on the stable ground. (a) Results of 2009-2010 time series; (b) Results of 2012-2013 time series. Acquisition date is displayed in the format of 'yyyymmdd'.

The centroid location of every Gaussian peak was taken as a reference to correct the centroid offsets for corresponding histograms of range/azimuth offsets derived from the landslide blocks. After correction, the histograms (referred to as "calibrated histograms" in this paper) of the 2D deformation fields derived from the stable ground adjacent to the landslide area are shown in Figure 14.
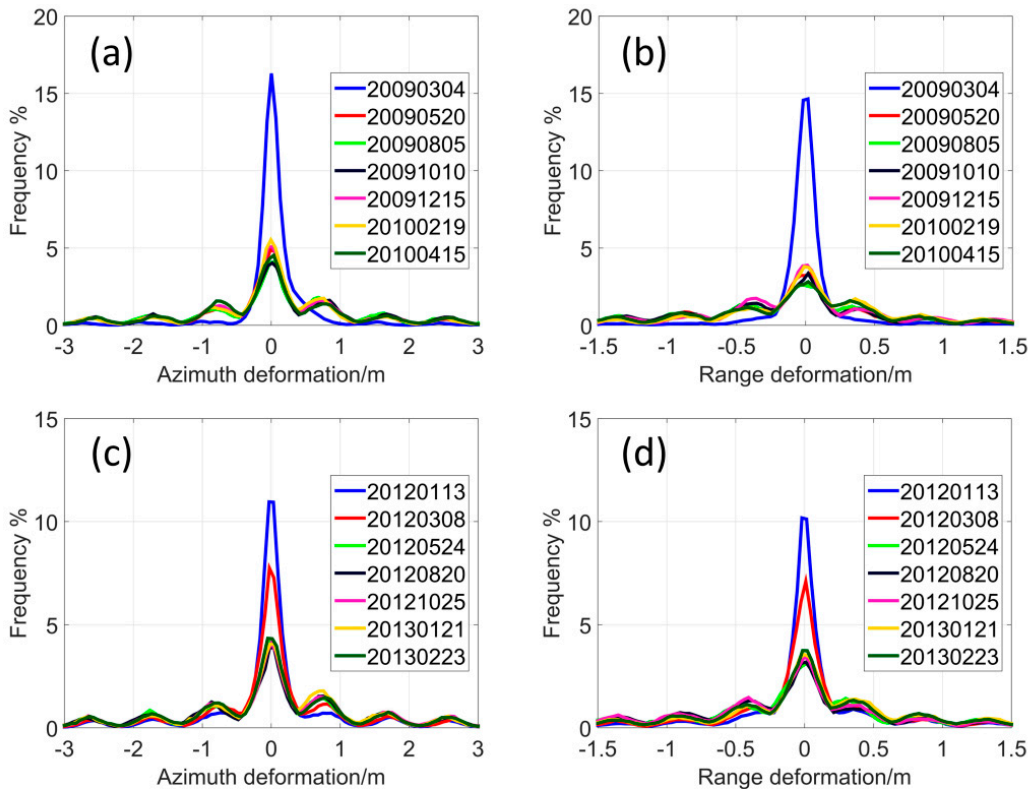

Figure 14. Calibrated time series histograms of $2 \mathrm{D}$ offsets derived from natural scatterers on the stable ground: (a) azimuth offsets derived from 2009-2010 time series of TSX HS data; (b) range offsets derived from 2009-2010 time series of TSX HS data; (c) azimuth offsets derived from 2012-2013 time series of TSX HS data; (d) range offsets derived from 2012-2013 time series of TSX HS data. Acquisition date is displayed in the format of 'yyyymmdd'.

In Figure 14, the calibrated histograms have the main lobe centered on the coordinate origin point with symmetrical small side lobes, indicating the calibration was successful.

The calibrated time series histograms of the azimuth/range displacement derived from the Shuping landslide blocks are shown in Figure 15.

In Figure 15, we can observe that the envelope of histograms slowly moves backwards (azimuth deformation) and forwards (range deformation) with time and the distribution of offsets gradually spread out indicating that different scatters have different landslide rates. 

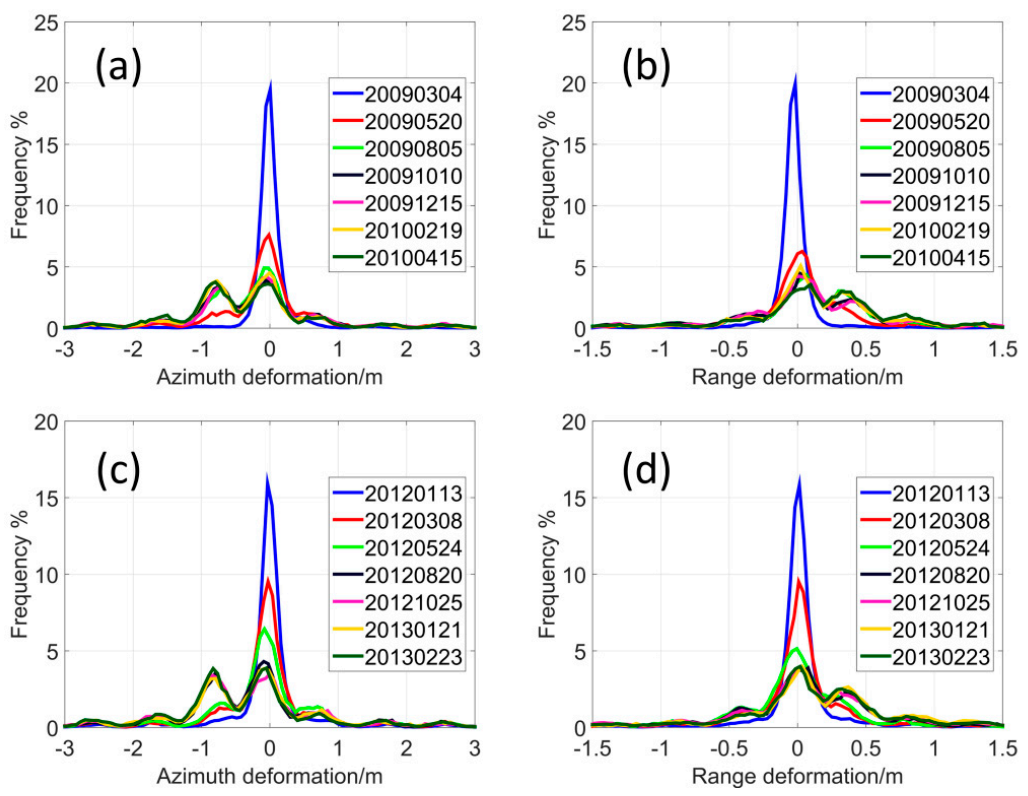

Figure 15. Calibrated time series histograms of 2D displacements derived from natural scatterers in the landslide area: (a) Azimuth deformation histograms of 2009-2010 time series; (b) Range deformation histograms of 2009-2010 time series; (c) Azimuth deformation histograms of 2012-2013 time series; (d) Range deformation histograms of 2012-2013 time series. Acquisition date is displayed in the format of 'yyyymmdd'. Modified from [66].

Using the correlation coefficient of 0.25 as the threshold, all pixels with correlation above this value are plotted to present the spatial distribution of azimuth and slant range displacements which occurred in February 2009-April 2010 and January 2012-February 2013, as shown in Figures 16 and 17. Range offsets beyond $-1-+1 \mathrm{~m}$ and azimuth offsets beyond $-2-+2 \mathrm{~m}$ are removed for better visualization. The two displacement intervals are identified on the histograms.
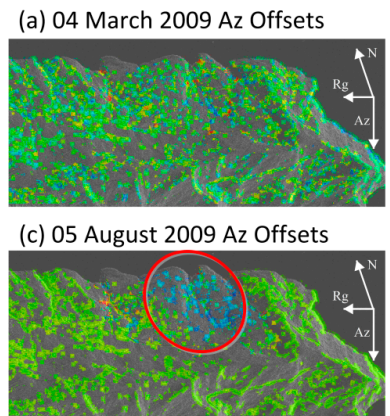

(e) 15 April $2010 \mathrm{Az}$ Offsets

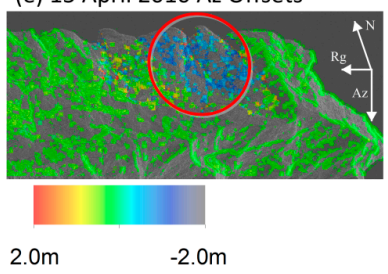

(b) 04 March 2009 Rg Offsets

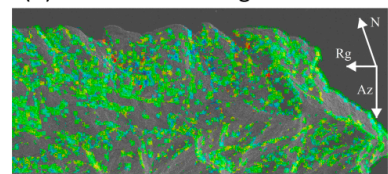

(d) 05 August 2009 Rg Offsets

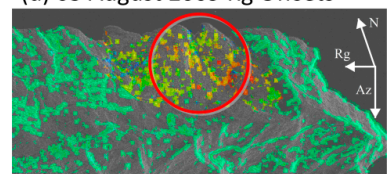

(f) 15 April 2010 Rg Offsets

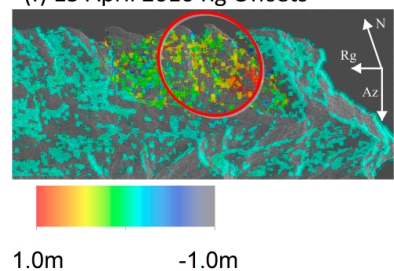

Figure 16. Spatial distribution of the 2D displacement measured from the whole area. (a,b) Azimuth/range offsets of the 21 February 2009-4 March 2009 pair; (c,d) Azimuth/range offsets of the 21 February 2009-5 August 2009 pair; (e,f) Azimuth/range offsets of the 21 February 2009-15 April 2010 pair. The arrows marked as "N, Rg, Az" refer to the North, slant range and azimuth directions. All these scatterers have correlation coefficient no less than 0.25 . 
(a) 13 January $2012 \mathrm{Az}$ Offsets

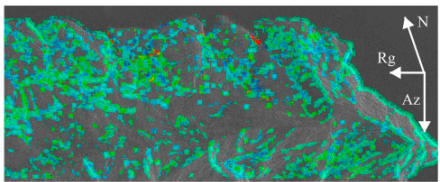

(c) 20 August $2012 \mathrm{Az}$ Offsets

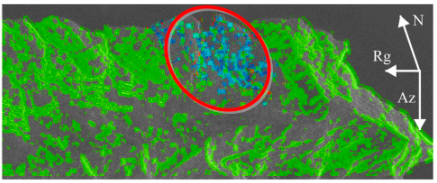

(e) 23 February 2013 Az Offsets

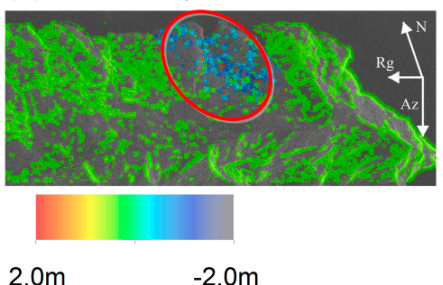

(b) 13 January 2012 Rg Offsets

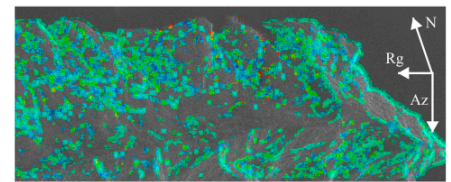

(d) 20 August 2012 Rg Offsets

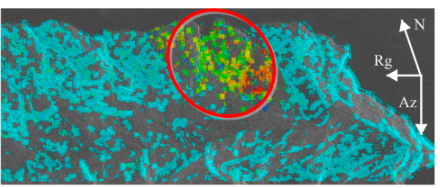

(f) 23 February 2013 Rg Offsets

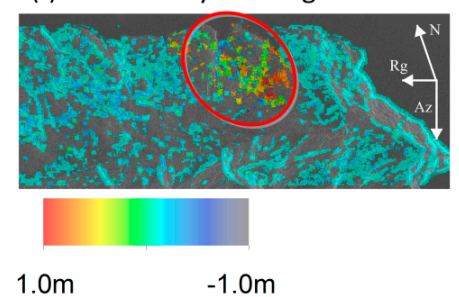

Figure 17. Spatial distribution of the 2D displacement measured from the whole area. (a,b) Azimuth/range offsets of the 2 January 2012-13 January 2012 pair; (c,d) Azimuth/range offsets of the 2 January 2012-20 August 2012 pair; (e,f) Azimuth/range offsets of the 2 January 2012-23 February 2013 pair. The arrows marked as "N, Rg, Az" refer to the North, slant range and azimuth directions. All these scatterers have correlation coefficient no less than 0.25 .

\section{Discussion}

\subsection{Performance Assessment of sPOT on Vegetated Surface}

The performance of sPOT in the vegetated areas is assessed by cumulative histograms of azimuth and range offsets $[20,67]$ derived from a rectangular area $\left(242,035 \mathrm{~m}^{2}\right)$ on the stable ground adjacent to the landslide body. In COSI_Corr, the sub-pixel accuracy is achieved by a quadratic polynomial interpolation of the correlation peak instead of oversampling the SAR intensities. Therefore, we only alter the correlation window size in the tests.

Cumulative Distribution Functions (CDFs) of azimuth/range displacements are plotted for different correlation window sizes, as shown in Figure 18.
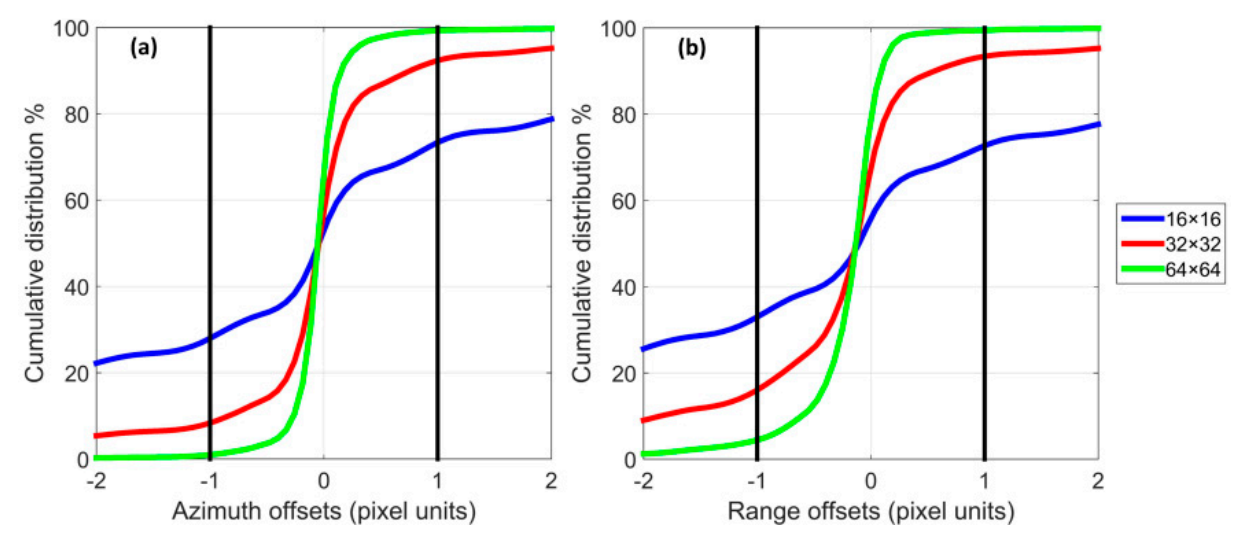

Figure 18. (a) Cumulative histograms of azimuth offsets derived from the vegetated surface over a stable area adjacent to the landslide body; (b) Cumulative histograms of range offsets derived from the vegetated surface over a stable area adjacent to the landslide body. This is plotted for different correlation window sizes of $16 \times 16,32 \times 32$ and $64 \times 64$. 
The elapsed time of each parameter setting in a 64 bit Windows 7 system (processor speed: $2.3 \mathrm{GHz}, \mathrm{RAM}: 8 \mathrm{~GB}$ ) is listed in Table 4.

Table 4. Processing Time Corresponding to Different Window Sizes of Cross-Correlation, Taking Into Account the Time Consumption of Image Co-Registration.

\begin{tabular}{cc}
\hline Correlation Window Size & Processing Time \\
\hline $16 \times 16$ & $30 \mathrm{~min}$ \\
$32 \times 32$ & $39 \mathrm{~min}$ \\
$64 \times 64$ & $78 \mathrm{~min}$ \\
\hline
\end{tabular}

We can see that using a correlation window size of $32 \times 32$, in the CDFs of both azimuth and range displacements, over $75 \%$ of pixels are characterised by displacements around zero and within \pm 1.0 pixel offset range. A larger window size improves the accuracy but dramatically increases the processing time (detailed in Table 4). Larger window sizes also increase artifacts and reduce the resolution of the deformation fields [67]. In the above experiments, it is found that a $32 \times 32$ correlation window size fulfils the research objectives with a reasonable time consumption and is therefore chosen in the processing for both CRs and vegetated surface.

Slight offsets of the centroid are observed from the CDFs of azimuth/range displacements (Figure 18), which very likely results from the impact of dense vegetative cover. This is also pointed out in Section 4.3 via the time series histograms of 2D deformation derived from stable ground, which can be corrected by the proposed calibration technique. As long as the majority of the pixels are characterised with deformation around a certain magnitude within a reasonable offset range, the parameters are considered satisfactory to provide sufficient robustness for sPOT method in the vegetated terrain.

\subsection{Accuracy Assessment of Sub-Pixel Offset Tracking (sPOT)}

The applicability of sPOT techniques to monitor landslides is determined by their accuracy, which consists of image co-registration errors and the uncertainty associated with Cross Correlation. In theory, the uncertainty of Cross Correlation can be calculated as the standard deviation error of the determination of the correlation peak [68], expressed as follows:

$$
\sigma=\sqrt{\frac{3}{10 N}} \frac{\sqrt{2+5 \gamma^{2}-7 \gamma^{4}}}{\pi \gamma^{2}}
$$

where $\gamma$ is the cross-correlation coefficient; $N$ is the number of independent samples involved in the Cross Correlation, referring to the original image resolution element. The correlation peak is then interpolated using a quadratic polynomial for $1 / 4$ pixel accuracy.

Thus, with a correlation window size of $32 \times 32$ and a correlation coefficient no less than 0.783 for all CRs, the Cross Correlation has an uncertainty of 0.02 pixels. This is validated by a simulation of cross-correlation using the same parameters with the image acquired on 21 February 2009 as the master and the same image shifted by 5 pixels in slant range direction and 8 pixels in inverse azimuth direction as the slave. The 2D offsets derived by the cross-correlation are analysed and shown in Table 5 . These results are obtained with the correlation coefficients ranging from 0.806 to 0.999 , almost the same correlation coefficients measured from CRs.

From Table 5, we can see that with the correlation coefficients of no less than 0.8 , the cross-correlation measures a mean offset of 5 pixels in the range direction and -8 pixels in the azimuth direction, exactly the same offsets as the image shifted prior to the simulation. The standard deviation errors are 0.022 pixels and 0.021 pixels respectively in the range and azimuth directions. This is in alignment with the theoretical uncertainty calculated for CRs (with a correlation coefficient no 
less than 0.783) using Equation (6). Thus, the calculated uncertainty is believed to be a good estimate of practical errors of cross-correlation.

Table 5. Statistics of range and azimuth offsets derived from the 20090221 image and the same image shifted by 5 pixels in range direction and 8 pixels in inverse azimuth direction.

\begin{tabular}{ccccc}
\hline & Mean (Pixel) & Std (Pixel) & Max (Pixel) & Min (Pixel) \\
\hline Range offset & 5.000 & 0.022 & 5.497 & 4.503 \\
Azimuth offset & -8.000 & 0.021 & -7.503 & -8.496 \\
\hline
\end{tabular}

It is worth noting that the coregistration is not perfect. The residual errors from the coregistration step may lead to uncompensated image offsets which can be mixed in with the investigated displacements [37]. Thus, the overall errors of offset tracking should consider the coregistration errors with the standard deviation errors of cross-correlation. Taking into account both of the cross-correlation uncertainty and the co-registration errors up to $1 / 10$ pixels, the theoretical accuracy of sPOT comes to 0.12 pixels. Substituting the range pixel spacing of $45.6 \mathrm{~cm}$ and azimuth pixel spacing of $86.2 \mathrm{~cm}$ of TSX Spotlight data into Equation (6), the accuracy of offsets measured from CRs is $5.5 \mathrm{~cm}$ in the range direction and $10.3 \mathrm{~cm}$ in the azimuth direction. Thus, the offset tracking technique has sufficient accuracy on CRs to monitor Shuping landslides with regard to the annual displacement rate up to $1 \mathrm{~m}$ in the azimuth direction and up to $0.7 \mathrm{~m}$ in the range direction.

The corner reflector measurements were compared with the results of the same period presented in [20], the differences between slant range/azimuth offsets are shown in Table 6.

Table 6. Comparison between the corner reflector measurements derived in this study and the results presented in a previous study [20].

\begin{tabular}{cccc}
\hline & Mean Difference (m) & Standard Deviation (m) & RMS Errors (m) \\
\hline Range offset & 0.006 & 0.031 & 0.032 \\
Azimuth offset & 0.025 & 0.084 & 0.088 \\
\hline
\end{tabular}

As shown in Table 6, the root mean square error (RMSE) of offset measurements is $0.088 \mathrm{~m}$ in azimuth direction and $0.032 \mathrm{~m}$ in range direction, both within the expected accuracy of corner reflector measurements, which reaches a good agreement from a statistical standpoint.

The accuracy of the offsets derived from natural scatterers in the vegetated terrain is assessed by simulation using the correlation coefficients of 21 February 2009-15 April 2010 image pair as inputs. The histogram of the correlation coefficients of natural scatterers is plotted in Figure 19. All contributions from artificial CRs were masked out before analysis.

The accuracy consists of the simulated uncertainties using Equation (6) and co-registration errors of 1/10 pixel size. The cumulative distributions of the 2D accuracy are shown in Figure 20.

From Figure 20, we can see that over $75 \%$ of natural scatterers have improved accuracy rates of $34 \mathrm{~cm}$ in the azimuth direction and $18 \mathrm{~cm}$ in the range direction. For a typical correlation coefficient of 0.25 , the lowest accuracy is $24 \mathrm{~cm}$ in the azimuth direction and $13 \mathrm{~cm}$ in the range direction. Hence, the accuracy of the natural scatterers is statistically significant in measuring the Shuping landslides with regard to the annual displacement rate up to $1 \mathrm{~m}$ in the azimuth direction and $0.7 \mathrm{~m}$ in the range direction. 


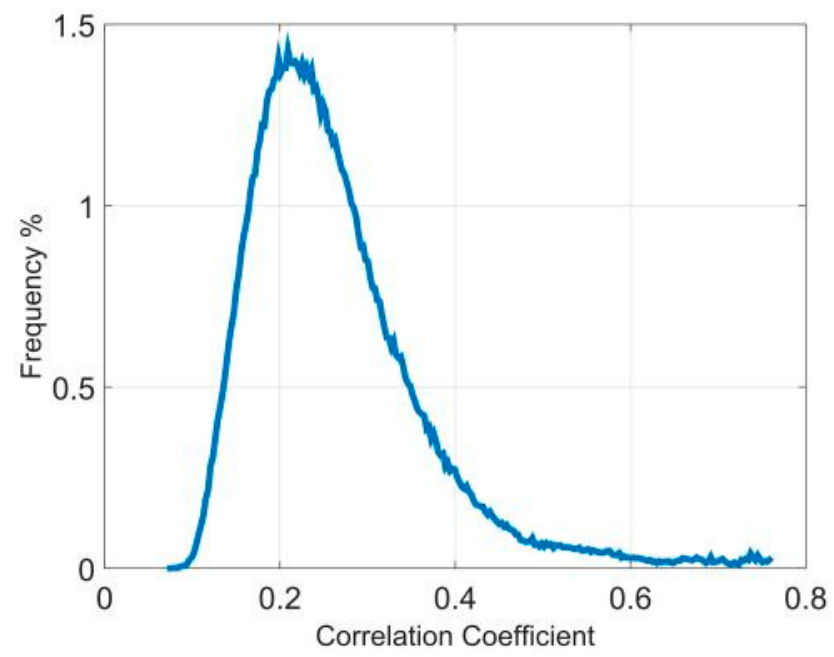

Figure 19. Histogram of the correlation coefficients of 21 February 2009-15 April 2010 image pair processed by sPOT method, the contributions from corner reflectors have been masked out before the assessment.
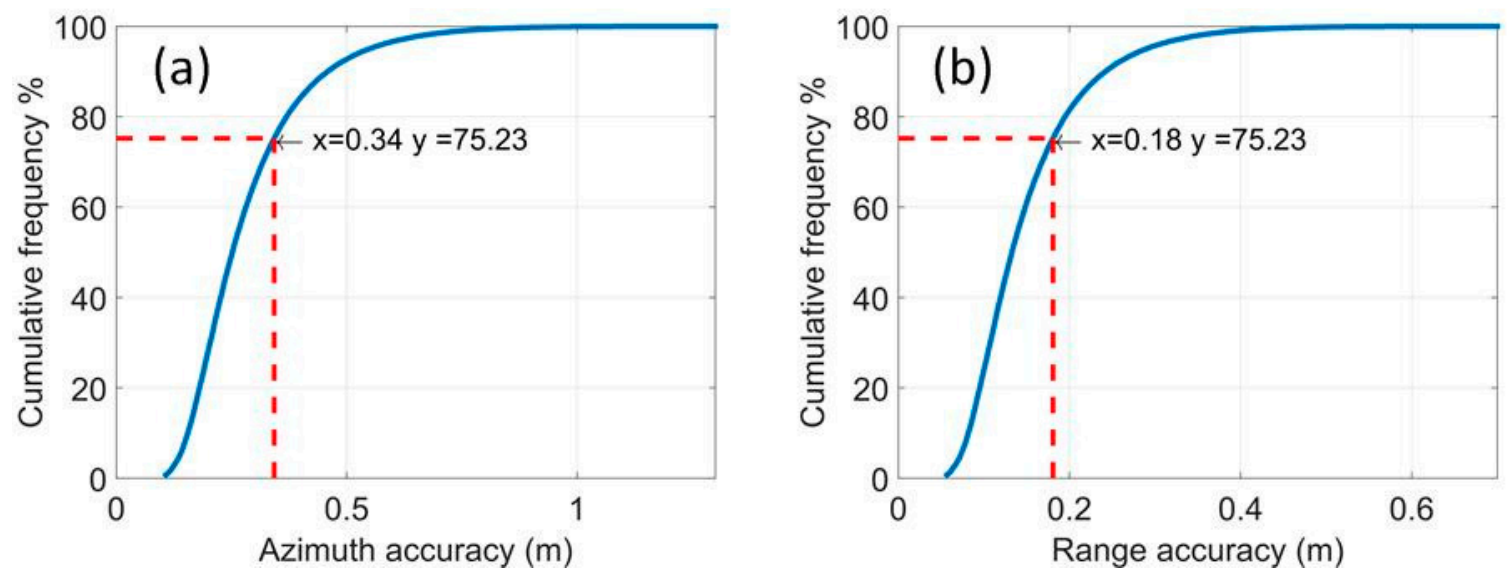

Figure 20. (a) Cumulative distributions of the accuracy of azimuth displacements derived from natural scatterers; (b) Cumulative distributions of the accuracy of range displacements derived from natural scatterers. Both of the Cross Correlation uncertainty and co-registration errors are considered.

\subsection{Validation of Derived Shuping Landslide Rates}

Due to the lack of availability of in-situ measurements of CRs in the Shuping landslide area, the offset tracking results are verified by the extensometer measurements presented by Wang et al. [23] on the eastern block of the Shuping landslide (where CR7-11 is located).

The measured range and azimuth deformation represent the components of the actual displacement projected on the slant range and azimuth directions. The displacement vector measured by extensometers is along the slope surface and centreline of the eastern block [23], approximately along the gradient of the elevation model. Slope degrees are derived using 1 arc-second SRTM DEM for each elevation value. By the decomposition of the extensometer measurements on to the North, East and Up directions, the azimuth and slant range offsets $\mathrm{dr}$ and da can be resolved using the following Equations [69]:

$$
\begin{aligned}
d_{r} & =-d_{u} \cos \theta_{i n c}+\sin \theta_{i n c}\left[d_{n} \cos \left(\alpha_{h}-\frac{3 \pi}{2}\right)+d_{e} \sin \left(\alpha_{h}-\frac{3 \pi}{2}\right)\right] \\
& =-d_{u} \cos \theta_{i n c}-d_{n} \sin \theta_{i n c} \sin \alpha_{h}+d_{e} \sin \theta_{i n c} \cos \alpha_{h}
\end{aligned}
$$




$$
\begin{aligned}
d_{a} & =d_{n} \sin \left(\alpha_{h}-\frac{3 \pi}{2}\right)-d_{e} \cos \left(\alpha_{h}-\frac{3 \pi}{2}\right) \\
& =d_{n} \cos \alpha_{h}+d_{e} \sin \alpha_{h}
\end{aligned}
$$

where $d_{u}, d_{n}, d_{e}$ are the Upward, Northward and Eastward displacement, $d_{r}$ and $d_{a}$ denote the range and azimuth displacement derived from SAR images, $\theta_{i n c}$ is the antenna incidence angle, $\alpha_{h}$ represents the satellite orbit heading (the angle formed between North and azimuth direction).

CR9 in the eastern block is selected for the comparison because its elevation of $277 \mathrm{~m}$ is closest to one of the extensometers "SP1-9" crossing the $275 \mathrm{~m}$ contour as presented in [23]. The SP1-9 shows $70 \mathrm{~cm}$ increase of displacement from February-August 2009.

With an orientation of $355^{\circ}$ (measured in Google Earth using the centreline of the eastern block), slope degrees of $22^{\circ}$ (derived from the DEM), accumulative displacement of $0.7 \mathrm{~m}$ is decomposed and inversed to the radar geometry using Equations (7) and (8). The inversion obtained $-0.62 \mathrm{~m}$ of azimuth displacement and $0.33 \mathrm{~m}$ of slant range displacement for the period of 1 February-01 August 2009. The accumulative displacements derived by offset tracking on CR7 for 21 February-5 August 2009 are $-0.6 \mathrm{~m}$ in the azimuth direction and $0.44 \mathrm{~m}$ in the range direction. We can see that the azimuth displacement derived by offset tracking is very close to the extensometer measurement with only a difference of $2 \mathrm{~cm}$, while the range displacement has a difference of $11 \mathrm{~cm}$. This is probably because the extensometer only measures the displacement projection along the orientation of the block $\left(355^{\circ}\right)$ approximately to the North and the decomposed range displacement is only part of the projection of actual displacement along the slant range. Overall, the extensometer measurements revealed a consistent pattern of all extensometers with a dramatic increase of the displacement from May to August 2009, which is in alignment with the pattern detected by offset tracking.

\subsection{Landslide Mechanism Inferred From This Study}

The landslide rates measured from the two annual time series show a consistent seasonal pattern of the deformation magnitude of all CRs located in the landslide blocks, whilst the displacements of CRs on the stable ground fluctuate around zero. The corner reflector measurements inside the landslide boundary show a dramatic increase over the same time period over both observation years (i.e., May to August in 2009 and 2012), which implies that the landslide is likely caused by the same driving factors.

In Figures 7 and 8, the measurements of CR9 and CR15 both show a strong correlation with the water level variations of Three Gorges Reservoir in 2009-2010 and 2012-2013 time series observation. It is evident that the landslide active period coincides with the sharp drawdown of the water level of the Three Gorges Dam Reservoir. This suggests a strong connection between the landslide displacements and the operation of the Three Gorges Dam. As there is no deformation observed after the big rise of water level in September, the failure mechanism can be considered as follows: When the reservoir water level increases, the voids of the soil are gradually filled with water during this process. Then the water level reaches its highest level $(175 \mathrm{~m})$ and remains in this level for a period. The ground water table gradually reaches a higher elevation and remains in this state. The pressure inside the landslide body balances with the pressure formed by the $175 \mathrm{~m}$ water level, which maintains the slope stability. When the water level sharply drops, the ground water content within the landslide body does not drop at the same rate. This results in greater water content inside the landslide body, which forms an outward pressure, leading to the loss of slope stability. However, as the water level drawdown happens synchronously with the seasonal rainfall variations (due to the drawdown being enacted to mitigate against flooding effects form the high seasonal rainfall), a further study is required to differentiate the impacts of these two factors to fully understand the mechanism of the Shuping landslide.

\subsection{Potential and Limitations of sPOT to Monitor Landslides in Densely Vegetated Areas}

The sub-Pixel Offset Tracking (sPOT) approach only utilizes intensity bands of the satellite imagery to retrieve 2D ground deformation. It is less sensitive to Atmospheric phase screening (APS) and 
low phase coherence, not requiring phase unwrapping which leads to most of the failures in DInSAR time series approaches due to the low density of Persistent Scatter points. Thus, sPOT techniques potentially has the capability and advantage of measuring the deformation of slope movements with the speed exceeding the maximum detectable displacement of DInSAR or map mass movements in challenging areas such as densely vegetated steep terrain.

The sPOT techniques can be applied in measuring surface deformation when the expected accuracy is sufficient. This is jointly determined by the deformation rates, availability of high-resolution imagery and surface features in the targeted area. Using hi-resolution SAR imagery, sPOT can be used for the monitoring of slow-moving landslides and complement other applications of DInSAR, since sPOT has no limitation on the maximum detectable deformation gradient (DDG) and is still applicable to deformation measurements in the direction perpendicular to satellite LOS.

The deformation rates of the Shuping landslide show that the maximum displacement assumption of DInSAR is not valid in this region, suggesting offset tracking is the only viable alternative method when high resolution imagery is available in order to achieve sufficient accuracy with regard to the displacement rates. Similar to the PSI and SBAS methods, the displacement derived by offset tracking is relative to the stable ground. The constant offsets were removed in the step of centroid shift correction. There can be several sources of the constant offsets, such as the seasonal changes of vegetation cover, the general change of backscatters due to different view angles between passes, etc.

In addition, when there is a lack of ground truth measurements, the results derived from another independent dataset can be utilized in the validation. Thus, for potentially unstable slopes, more than one dataset acquired over the same time period is important for deformation monitoring.

The proposed sPOT approach has been shown of being capable of measuring landslide rates in densely vegetated terrain. Instead of only measuring the deformation magnitude of sparsely distributed 17 CRs, this approach provides a synoptic overview of the deformation fields of all pixels in the landslide area by statistical analysis. From the centroid location changes of every annual time series histograms, the active period of Shuping landslide can be detected. In Figure 15, for both azimuth and range displacements, we can see the histogram centroid stays the same during from 21 February 2009-20 April 2009 and 2 January 2012-24 May 2012 and then shows a sudden change from May of each annual time series as well as a wider and split distribution of histograms. In the periods during 5 August 2009-15 April 2010 and 20 August 2012-23 February 2013 the centroid rarely moves with slight changes in the envelope shapes. From the statistical analysis, the active period of the Shuping landslide is identified as May to August annually, whilst after August, the slope tends to be relatively stable, which shows an accurate correlation with the corner reflector measurements. Offset maps (Figures 16 and 17) show the spatial distribution of the deformation and a distinguishable pattern representing the ongoing landslide.

\section{Conclusions}

Monitoring of landslides using DInSAR in the Three Gorges Region has received extensive attention over recent years due to the challenges posed in this region. Sub-Pixel Offset Tracking (sPOT) is here shown as an alternative method to address several issues that DInSAR encountered in previous research.

In this study, we demonstrated the capability of sub-Pixel Offset Tracking (sPOT) techniques to monitor relatively fast slope movements in densely vegetated areas with and without the presence of artificial CRs. Although lower accuracy is expected by using sPOT, as long as the accuracy is sufficient with regard to the deformation rates in the study area, sPOT has the advantage of measuring ground displacement perpendicular to the satellite line-of-sight. In addition to DInSAR techniques, sPOT should also be applied to assess if the assumption of DInSAR can be fulfilled. As only SAR amplitude is employed in the processing, sPOT is less sensitive to changes of Atmospheric Phase Screen and low phase coherence. It is not limited by the maximum detectable displacement (MMD) of DInSAR or time series DInSAR as it is not based on any assumption required by phase unwrapping. 
Artificial CRs can help to achieve higher accuracy for ground deformation measurements made from sPOT measurements in densely vegetated terrain, whist in the vast majority of regions where such high-contrast features are not available, the proposed approach is able to independently measure ground deformation in terms of the detection of the landslide scale, active period and distribution of deformation magnitude of all the scatterers for the whole landslide area.

In this paper, the statistical analysis of landslide rates derived over vegetated surfaces shows a dramatic increase of landslide displacement rates in the time period approximately from May to August in 2009-2010 and 2012-2013. In each annual time series, the landslide active period coincided with a large drawdown of the reservoir water level in the flood season, suggesting that in Shuping there is a strong connection between the formation of landslides and the operation of the Three Gorges Dam.

Acknowledgments: This research is linked to the ESA-MOST DRAGON-3 Project \#10665: Monitoring ground surface displacements in China from EO through case studies of landslides in the Three Gorges Area, crustal tectonic movement in Tibet and subsidence in South China. The work is supported by the UCL Dean's Prize and China Scholarship Council Scholarship. The TerraSAR-X data employed in this study was provided by the German Aerospace Centre (DLR) under data grant GEO0112. We thank J. Zhang, Q. Jiao and T. Xue from China Earthquake Administration for support on fieldwork, and A. Singleton from the University of Glasgow for providing CR measurements for comparison. COSI_Corr was downloaded from http://www.tectonics.caltech.edu/slip_history/spot_coseis/download_software.html for non-commercial research.

Author Contributions: First draft by L. Sun; Supervision and selection of areas by J.-P. Muller as well as editing of original and revised manuscripts prior to submission; Joint field work by L. Sun and J.-P. Muller in the area in May 2014.

Conflicts of Interest: The authors declare no conflict of interest. The founding sponsors had no role in the design of the study; in the collection, analyses, or interpretation of data; in the writing of the manuscript, and in the decision to publish the results.

\section{References}

1. Liao, M.; Tang, J.; Wang, T.; Balz, T.; Zhang, L. Landslide monitoring with high-resolution sar data in the Three Gorges Region. Sci. China Earth Sci. 2012, 55, 590-601. [CrossRef]

2. Wang, Z.H. Remote sensing in the preparatory work of China's hydropower construction. Remote Sens. Land Resour. 1995, 7, 1-8.

3. Perski, Z.; Wojciechowski, T.; Borkowski, A. Persistent scatterer sar interferometry applications on landslides in carpathians (Southern Poland). Acta Geodyn. Geomater. 2010, 7, 1-7.

4. Gabriel, A.K.; Goldstein, R.M.; Zebker, H.A. Mapping small elevation changes over large areas: Differential radar interferometry. J. Geophys. Res. 1989, 94, 9183-9191. [CrossRef]

5. Goldstein, R.M.; Engelhardt, H.; Kamb, B.; Frolich, R.M. Satellite radar interferometry for monitoring ice sheet motion: Application to an antarctic ice stream. Science 1993, 262, 1525-1530. [CrossRef] [PubMed]

6. Massonnet, D.; Rossi, M.; Carmona, C.; Adragna, F.; Peltzer, G.; Feigl, K.; Rabaute, T. The displacement field of the landers earthquake mapped by radar interferometry. Nature 1993, 364, 138-142. [CrossRef]

7. Zebker, H.A.; Rosen, P. On the derivation of coseismic displacement fields using differential radar interferometry: The landers earthquake. In Proceedings of the IEEE International Geoscience and Remote Sensing Symposium, Surface and Atmospheric Remote Sensing: Technologies, Data Analysis and Interpretation, Pasadena, CA, USA, 8-12 August 1994; pp. 286-288.

8. Shan, X.; Ma, J.; Wang, C.; Liu, J.; Song, X.; Zhang, G. Co-seismic ground deformation and source parameters of Mani M7.9 earthquake inferred from spaceborne D-InSAR observation data. Sci. China Earth Sci. 2004, 47, 481-488. [CrossRef]

9. Colesanti, C.; Wasowski, J. Investigating landslides with space-borne synthetic aperture radar (SAR) interferometry. Eng. Geol. 2006, 88, 173-199. [CrossRef]

10. Tomas, R.; Herrera, G.; Lopez-Sanchez, J.M.; Vicente, F.; Cuenca, A.; Mallorquí, J.J. Study of the land subsidence in Orihuela city (SE Spain) using PSI data: Distribution, evolution and correlation with conditioning and triggering factors. Eng. Geol. 2010, 115, 105-121. [CrossRef] 
11. Milillo, P.; Fielding, E.J.; Shulz, W.H.; Delbridge, B.; Burgmann, R. Cosmo-skymed spotlight interferometry over rural areas: The slumgullion landslide in colorado, USA. IEEE J. Sel. Top. Appl. Earth Obs. Remote Sens. 2014, 7, 2919-2926. [CrossRef]

12. Liu, D.; Shao, Y.; Liu, Z.; Riedel, B.; Sowter, A.; Niemeier, W.; Bian, Z. Evaluation of InSAR and TomoSAR for monitoring deformations caused by mining in a mountainous area with high resolution satellite-based SAR. Remote Sens. 2014, 6, 1476-1495. [CrossRef]

13. Fernández, J.; Romero, R.; Carrasco, D.; Luzón, F.; Araña, V. InSAR volcano and seismic monitoring in Spain. Results for the period 1992-2000 and possible interpretations. Opt. Lasers Eng. 2002, 37, 285-297. [CrossRef]

14. Ferretti, A.; Prati, C.; Rocca, F. Permanent scatterers in SAR interferometry. IEEE Trans. Geosci. Remote Sens. 2001, 39, 8-20. [CrossRef]

15. Hooper, A.; Zebker, H.; Segall, P.; Kampes, B. A new method for measuring deformation on volcanoes and other natural terrains using InSAR persistent scatterers. Geophys. Res. Lett. 2004. [CrossRef]

16. Ferretti, A.; Savio, G.; Barzaghi, R.; Borghi, A.; Musazzi, S.; Novali, F.; Prati, C.; Rocca, F. Submillimeter accuracy of InSAR time series: Experimental validation. IEEE Trans. Geosci. Remote Sensi. 2007, 45, 1142-1153. [CrossRef]

17. Lundgren, P.; Usai, S.; Sansosti, E.; Lanari, R.; Tesauro, M.; Fornaro, G.; Berardino, P. Modeling surface deformation observed with synthetic aperture radar interferometry at Campi Flegrei Caldera. J. Geophys. Res. Solid Earth 2001, 106, 19355-19366. [CrossRef]

18. Berardino, P.; Fornaro, G.; Lanari, R.; Sansosti, E. A new algorithm for surface deformation monitoring based on small baseline differential SAR interferograms. IEEE Trans. Geosci. Remote Sens. 2002, 40, 2375-2383. [CrossRef]

19. Muller, J.; Zeng, Q.; Li, Z.; Liu, J.; Austin, N.; Brown, D.; Nightingale, M.; Zhang, J.; Gong, L.; Ouyang, Z. Dragon Project 2558: Exploitation of SAR and optical imagery for monitoring the environmental impacts of the Three Gorges Dam. In Proceedings of the 2008 Dragon Symposium, Beijing, China, 21-25 April 2008.

20. Singleton, A.; Li, Z.; Hoey, T.; Muller, J.P. Evaluating sub-pixel offset techniques as an alternative to D-InSAR for monitoring episodic landslide movements in vegetated terrain. Remote Sens. Environ. 2014, 147, $133-144$. [CrossRef]

21. Fu, W.; Guo, H.; Tian, Q.; Guo, X. Landslide monitoring by corner reflectors differential interferometry SAR. Int. J. Remote Sens. 2010, 31, 6387-6400. [CrossRef]

22. Xia, Y. Synthetic aperture radar interferometry. In Sciences of Geodesy I: Advances and Future Directions; Xu, G., Ed.; Springer: Berlin/Heidelberg, Germany, 2010; pp. 415-474.

23. Wang, F.; Yin, Y.; Huo, Z.; Zhang, Y.; Wang, G.; Ding, R. Slope deformation caused by water-level variation in the Three Gorges Reservoir, China. In Landslides: Global Risk Preparedness; Sassa, K., Rouhban, B., Briceño, S., McSaveney, M., He, B., Eds.; Springer: Berlin/Heidelberg, Germany, 2013; pp. 227-237.

24. Chen, C.W.; Zebker, H.A. Network approaches to two-dimensional phase unwrapping: Intractability and two new algorithms. J. Opt. Soc. Am. A 2000, 17, 401-414. [CrossRef]

25. Cruden, D.M.; Varnes, D.J. Landslide types and processes. In Landslides: Investigation and Mitigation; Transportation Research Board: Washington, DC, USA, 1996; pp. 36-75.

26. Hungr, O.; Leroueil, S.; Picarelli, L. The varnes classification of landslide types, an update. Landslides 2014, 11, 167-194. [CrossRef]

27. Longoni, L.; Papini, M.; Brambilla, D.; Arosio, D.; Zanzi, L. The role of the spatial scale and data accuracy on deep-seated gravitational slope deformation modeling: The Ronco Landslide, Italy. Geomorphology 2016, 253, 74-82. [CrossRef]

28. Brückl, E.; Brunner, F.; Lang, E.; Mertl, S.; Müller, M.; Stary, U. The gradenbach observatory-Monitoring deep-seated gravitational slope deformation by geodetic, hydrological, and seismological methods. Landslides 2013, 10, 815-829. [CrossRef]

29. Michel, R.; Avouac, J.P.; Taboury, J. Measuring ground displacements from SAR amplitude images: Application to the landers earthquake. Geophys. Res. Lett. 1999, 26, 875-878. [CrossRef]

30. Kääb, A. Monitoring high-mountain terrain deformation from repeated air and spaceborne optical data: Examples using digital aerial imagery and ASTER data. ISPRS J. Photogramm. Remote Sens. 2002, 57, $39-52$. [CrossRef] 
31. Yamaguchi, Y.; Tanaka, S.; Odajima, T.; Kamai, T.; Tsuchida, S. Detection of a landslide movement as geometric misregistration in image matching of SPOT HRV data of two different dates. Int. J. Remote Sens. 2003, 24, 3523-3534. [CrossRef]

32. Delacourt, C.; Allemand, P.; Casson, B.; Vadon, H. Velocity field of the "la clapière" landslide measured by the correlation of aerial and quickbird satellite images. Geophys. Res. Lett. 2004. [CrossRef]

33. Wangensteen, B.; Guðmundsson, Á.; Eiken, T.; Kääb, A.; Farbrot, H.; Etzelmüller, B. Surface displacements and surface age estimates for creeping slope landforms in Northern and Eastern Iceland using digital photogrammetry. Geomorphology 2006, 80, 59-79. [CrossRef]

34. Debella-Gilo, M.; Kääb, A. Sub-pixel precision image matching for measuring surface displacements on mass movements using normalized cross-correlation. Remote Sens. Environ. 2011, 115, 130-142. [CrossRef]

35. Bennett, G.; Roering, J.; Mackey, B.; Handwerger, A.; Schmidt, D.; Guillod, B. Historic drought puts the brakes on earthflows in Northern California. Geophys. Res. Lett. 2016. [CrossRef]

36. Strozzi, T.; Luckman, A.; Murray, T.; Wegmuller, U.; Werner, C.L. Glacier motion estimation using SAR offset-tracking procedures. IEEE Trans. Geosci. Remote Sens. 2002, 40, 2384-2391. [CrossRef]

37. Casu, F.; Manconi, A.; Pepe, A.; Lanari, R. Deformation time-series generation in areas characterized by large displacement dynamics: The SAR amplitude pixel-offset SBAS technique. IEEE Trans. Geosci. Remote Sens. 2011, 49, 2752-2763. [CrossRef]

38. Casu, F.; Manconi, A. Four-dimensional surface evolution of active rifting from spaceborne SAR data. Geosphere 2016, 12, 697-705. [CrossRef]

39. Manconi, A.; Casu, F.; Ardizzone, F.; Bonano, M.; Cardinali, M.; De Luca, C.; Gueguen, E.; Marchesini, I.; Parise, M.; Vennari, C.; et al. Brief communication: Rapid mapping of landslide events: The 3 December 2013 montescaglioso landslide, Italy. Nat. Hazards Earth Syst. Sci. 2014, 14, 1835-1841. [CrossRef]

40. Elefante, S.; Manconi, A.; Bonano, M.; De Luca, C.; Casu, F. Three-dimensional ground displacements retrieved from SAR data in a landslide emergency scenario. In Proceedings of the 2014 IEEE Geoscience and Remote Sensing Symposium, Quebec City, QC, USA, 13-18 July 2014; pp. 2400-2403.

41. Raspini, F.; Ciampalini, A.; Del Conte, S.; Lombardi, L.; Nocentini, M.; Gigli, G.; Ferretti, A.; Casagli, N. Exploitation of amplitude and phase of satellite SAR images for landslide mapping: The case of Montescaglioso (South Italy). Remote Sens. 2015, 7, 14576-14596. [CrossRef]

42. Li, X. The Application of Sub-Pixel Correlation on the Measurement of Landslide Deformation-Taking the Shuping Landslide as an Example. Ph.D. Thesis, Peking University, Beijing, China, 2011.

43. Monserrat, O.; Moya, J.; Luzi, G.; Crosetto, M.; Gili, J.A.; Corominas, J. Non-interferometric GB-SAR measurement: Application to the vallcebre landslide (Eastern Pyrenees, Spain). Nat. Hazards Earth Syst. Sci. 2013, 13, 1873-1887. [CrossRef]

44. Raucoules, D.; De Michele, M.; Malet, J.P.; Ulrich, P. Time-variable 3D ground displacements from high-resolution synthetic aperture radar (SAR). Application to la valette landslide (South French Alps). Remote Sens. Environ. 2013, 139, 198-204. [CrossRef]

45. Jiao, M.; Song, L.; Wang, J.; Ke, Y.; Zhang, C.; Zhou, T.; Xu, Y.; Jiang, T.; Zhu, C.; Chen, X.; et al. Addressing the potential climate effects of China's Three Gorges project. Water Energy Int. 2013, 70, 59-60.

46. Wang, T.; Perissin, D.; Liao, M.; Rocca, F. Deformation monitoring by long term D-InSAR analysis in Three Gorges Area, China. In Proceedings of the IGARSS 2008-2008 IEEE International Geoscience and Remote Sensing Symposium, Boston, MA, USA, 7-11 July 2008; pp. IV-5-IV-8.

47. Wang, T.; Perissin, D.; Rocca, F.; Liao, M.-S. Three Gorges Dam stability monitoring with time-series InSAR image analysis. Sci. China Earth Sci. 2011, 54, 720-732. [CrossRef]

48. Müller, B.; Berg, M.; Yao, Z.P.; Zhang, X.F.; Wang, D.; Pfluger, A. How polluted is the Yangtze River? Water quality downstream from the Three Gorges Dam. Sci. Total Environ. 2008, 402, 232-247. [CrossRef] [PubMed]

49. Wu, J.; Gao, X.; Giorgi, F.; Chen, Z.; Yu, D. Climate effects of the Three Gorges Reservoir as simulated by a high resolution double nested regional climate model. Quat. Int. 2012, 282, 27-36. [CrossRef]

50. Xu, K.; Milliman, J.D. Seasonal variations of sediment discharge from the Yangtze River before and after impoundment of the Three Gorges Dam. Geomorphology 2009, 104, 276-283. [CrossRef]

51. Xu, X.; Tan, Y.; Yang, G.; Li, H.; Su, W. Impacts of China's Three Gorges Dam project on net primary productivity in the reservoir area. Sci. Total Environ. 2011, 409, 4656-4662. [CrossRef] [PubMed]

52. Zhao, F.; Shepherd, M. Precipitation changes near Three Gorges Dam, China. Part I: A spatiotemporal validation analysis. J. Hydrol. 2011, 13, 735-745. [CrossRef] 
53. Guo, H.; Hu, Q.; Zhang, Q.; Feng, S. Effects of the Three Gorges Dam on Yangtze River flow and river interaction with Poyang Lake, China: 2003-2008. J. Hydrol. 2012, 416-417, 19-27. [CrossRef]

54. Wang, F.; Zhang, Y.; Huo, Z.; Peng, X.; Araiba, K.; Wang, G. Movement of the shuping landslide in the first four years after the initial impoundment of the Three Gorges Dam Reservoir, China. Landslides 2008, 5, 321-329. [CrossRef]

55. Chen, D.; Xue, G.; Xu, F. Study on the Engineering Geology Properties in Three Gorges; Hubei Science and Technology Publisher: Wuhan, China, 1997.

56. Sassa, K.; Fukuoka, H.; Wang, F.; Wang, G. Landslides: Risk Analysis and Sustainable Disaster Management; Springer Science \& Business Media: Berlin/Heidelberg, Germany, 2006.

57. Zitova, B.; Flusser, J. Image registration methods: A survey. Image Vis. Comput. 2003, 21, 977-1000. [CrossRef]

58. Li, X.; Muller, J.-P.; Fang, C.; Zhao, Y. Measuring displacement field from TerraSAR-X amplitude images by sub-pixel correlation: An application to the landslide in shuping, Three Gorges Area. Acta Petrol. Sin. 2011, 27, 3843-3850.

59. Leprince, S.; Ayoub, F.; Klingert, Y.; Avouac, J.P. Co-registration of optically sensed images and correlation (COSI-Corr): An operational methodology for ground deformation measurements. In Proceedings of the Geoscience and Remote Sensing Symposium, Barcelona, Spain, 23-28 July 2007; pp. 1943-1946.

60. Leprince, S.; Barbot, S.; Ayoub, F.; Avouac, J.P. Automatic and precise orthorectification, coregistration, and subpixel correlation of satellite images, application to ground deformation measurements. IEEE Trans. Geosci. Remote Sens. 2007, 45, 1529-1558. [CrossRef]

61. Ayoub, F.; Leprince, S.; Avouac, J.-P. Co-registration and correlation of aerial photographs for ground deformation measurements. ISPRS J. Photogramm. Remote Sens. 2009, 64, 551-560. [CrossRef]

62. Xia, Y.; Kaufmann, H.; Guo, X.F. Landslide monitoring in the Three Gorges Area using D-InSAR and corner reflectors. Photogramm. Eng. Remote Sens. 2004, 70, 1167-1172.

63. Liu, J.G.; Mason, P.J.; Clerici, N.; Chen, S.; Davis, A.; Miao, F.; Deng, H.; Liang, L. Landslide hazard assessment in the Three Gorges Area of the Yangtze river using ASTER imagery: Zigui-Badong. Geomorphology 2004, 61, 171-187. [CrossRef]

64. Bai, S.-B.; Wang, J.; Lü, G.-N.; Zhou, P.-G.; Hou, S.-S.; Xu, S.-N. Gis-based logistic regression for landslide susceptibility mapping of the Zhongxian segment in the Three Gorges Area, China. Geomorphology 2010, 115, 23-31. [CrossRef]

65. Xu, X.; Tan, Y.; Yang, G. Environmental impact assessments of the Three Gorges project in China: Issues and interventions. Earth-Sci. Rev. 2013, 124, 115-125. [CrossRef]

66. Sun, L.; Muller, J.-P.; Singleton, A.; Li, Z.; Liu, D.; Riedel, B.; Niemeier, W.; Liang, C.; Zeng, Q.; Jiao, J. Monitoring ground surface displacements in the Three Gorges area, crustal tectonic movement in Tibet and subsidence in South China. In Proceedings of the Dragon 3Mid Term Results, Chengdu, China, 26-29 May 2015.

67. Yun, S.H.; Zebker, H.; Segall, P.; Hooper, A.; Poland, M. Interferogram formation in the presence of complex and large deformation. Geophys. Res. Lett. 2007. [CrossRef]

68. De Zan, F. Accuracy of incoherent speckle tracking for circular gaussian signals. IEEE Geosci. Remote Sens. Lett. 2014, 11, 264-267. [CrossRef]

69. Hanssen, R.F. Radar Interferometry: Data Interpretation and Error Analysis; Springer: New York, NY, USA, 2001.

(C) 2016 by the authors; licensee MDPI, Basel, Switzerland. This article is an open access article distributed under the terms and conditions of the Creative Commons Attribution (CC-BY) license (http://creativecommons.org/licenses/by/4.0/). 